\title{
IV. Britisch-deutsche Allianz gegen den Young-Plan
}

Beifall hatte die deutsch-österreichische Aktion nur dort gefunden, wo stärkstes Interesse an der Fortdauer der Spaltung Europas in Verteidiger und Gegner des Status quo bestand, konkret also und vor allem Interesse an der Kontinuität des deutsch-französischen Gegensatzes. In einem gewissen Sinne war das in Warschau der Fall. Zwar wurde der polnische Gesandte in Berlin, Alfred Wysocki, im Auswärtigen Amt vorstellig, um darzutun, welch große Erregung die Verkündung der Zollunion auch in Polen hervorgerufen habe; in dem Vorhaben erkenne man Deutschlands Streben nach der Hegemonie im Südosten Europas ${ }^{1}$. Dennoch urteilte Adolf v. Moltke, der Rauscher in Warschau gefolgt war, wohl richtig: Im Grunde seien die Polen nicht unglücklich, wenn die Stoßrichtung des Deutschen Reiches nach Südosten abgelenkt werde, in erster Linie begrüßten sie jedoch das von dem Unternehmen voraussichtlich bewirkte Ansteigen der deutsch-französischen Spannung2; dies war ja sehr geeignet, etwaige Pariser Neigungen, auf Kosten Polens mit Deutschland politische Geschäfte zu machen - solche Sorgen plagen seit eh und je die Außenpolitiker aller Regierungen -, in Schach und die französische Schutzfunktion für Polen intakt zu halten.

Aus Moskau wiederum meldete Herbert v. Dirksen, die sowjetischen Führer hätten das Projekt mit leicht verständlicher Sympathie aufgenommen: „... leicht verständlich, weil die Unterhöhlung der Briand'schen Konzeption von Paneuropa und eine Verschärfung der deutsch-französischen Beziehungen zwei schwere Sorgen der Sowjetregierung mindert und die Hoffnung auf eine Spaltung der Kleinen Entente ihr zusagt. "3 In Warschau wie in Moskau dominierte jedenfalls die Annahme, Deutschland habe den so unwillkommenen Prozeß der deutsch-französischen Annäherung grundsätzlich gefährdet und zumindest vorübergehend gestoppt. In der Tat hätte die Zollunion, nach dem revisionistischen Getrommel, das ihr vorhergegangen war, eigentlich die fast totale außenpolitische Isolierung Deutschlands von revisionistischen Staaten wie der Sowjetunion abgesehen - bringen müssen. Gerade das trat indes nicht ein.

Rettung brachten mehrere Faktoren und Umstände. An erster Stelle stand die kontinuierliche und weltweite Verschlechterung der Wirtschaftslage. An

\footnotetext{
Aufzeichnung Köpke, 9. 4. 1931; PA, R 28322 k.

Moltke an AA, 26. 3. 1931; PA, R $28322 \mathrm{k}$.

3 Dirksen an AA, 13. 4. 1931; PA, R 70025.
} 
zweiter Stelle wirkte die britische Entschlossenheit, gegenüber Deutschland um nahezu jeden Preis Appeasement-Politik zu verfolgen. An dritter Stelle ist die Unmöglichkeit einer Rückkehr Frankreichs zu harten deutschlandpolitischen Konzeptionen und Methoden zu sehen. Viertens blieb der faschistische Imperialismus Italiens und mit ihm die italienisch-französische Gegnerschaft weiterhin im Spiel. Und schließlich war da die Furcht vor einer Ablösung der Regierung Brüning durch Deutschnationale und Nationalsozialisten.

Die Weltwirtschaftskrise kam Deutschland - so mißverständlich das auch klingen mag - auf mehrfache Weise zugute. Sie erfaßte allmählich alle Industrie- und Agrarstaaten - zunächst noch am wenigsten Frankreich -, und so nahm in den Nationen und Ländern das Verständnis zu, wenn andere Nationen und Länder über ihre wirtschaftliche Lage klagten. Damit wuchs automatisch auch die Einsicht, daß gehandelt und geholfen werden müsse. Nun war nicht zu übersehen, daß in Europa Deutschland und die mitteleuropäischen Staaten am übelsten dran waren und daß deren Notlage auch außerhalb der Region allenthalben krisenverschärfend wirkte. Das lenkte die Aufmerksamkeit auf das Reich und legte es nahe, die allgemeine Wende durch eine Kräftigung Deutschlands einzuleiten. Außerdem: Als Ursachen des Niedergangs wurden gewiß auch der Preisverfall bei Agrarprodukten und Rohstoffen und die ebenso kurzsichtige - weil den Welthandel lähmende - wie egoistische Hochzollpolitik praktisch aller souveräner Staaten und Staatenblöcke diagnostiziert, doch galt die Krise je länger je mehr vor allem auch als globale Kreditkrise, die ihre Wurzeln in den vom Krieg hinterlassenen Schulden habe, das heißt in einer riesigen Bewegung von Geld, die lediglich politisch und nicht wirtschaftlich begründet, daher wirtschaftlich schädlich sei. In diesem Zusammenhang setzten sich namentlich in Großbritannien zwei Thesen durch ${ }^{4}$ : daß, erstens, die wirtschaftlich unsinnigsten und folglich schädlichsten Geldbewegungen die deutschen Reparationszahlungen seien und daß zweitens eine vernünftige Behandlung - also die Liquidierung - des anderen großen Komplexes, nämlich der Verzinsung und Amortisation der den Alliierten von den USA während des Krieges gewährten Kredite, ohnehin nur erreichbar sei, wenn zuvor das Reparationsproblem aus der Welt geschafft werde; die europäischen Schuldner der USA konnten Leistungen erst dann verweigern, wenn sie sich auf das Ausbleiben deutscher Gelder und auch moralisch auf die gegenüber Deutschland geübte Großmut zu berufen vermochten.

In den Vereinigten Staaten, wo öffentlich jedermann streng darauf hielt,

4 Hierzu Büsch/Witt (Hrsg.), Internationale Zusammenhänge. Dic britischen Auffassungen finden sich recht genau in dem am 19.8. 1931 veröffentlichten Bericht des von der Londoner Konferenz (20.-23. 7. 1931) bestellten Sachverständigen-Ausschusses, Schulthess', 1931, S. $509 \mathrm{ff}$; der englische Text, in London am 22. 8. 1931 veröffentlicht; DBFP, Second Series, Vol. II, Appendix II. 
daß man mit so etwas Schmutzigem wie Reparationen absolut nichts zu tun habe und daß nicht der kleinste Zusammenhang zwischen den deutschen Verpflichtungen und der Rückzahlung des England, Frankreich und sonstigen europäischen Staaten geliehenen Geldes bestehe, fanden sich in den Medien noch kaum Stimmen, die empfohlen hätten, die Kriegskredite abzuschreiben. Aber viele Bankiers und viele Angehörige der politischen Elite näherten sich den britischen Ansichten. So entstand eine Stimmung, die deutschem Aufbegehren gegen die Reparationslast günstig war, ja mittlerweile solches Aufbegehren im allgemeinen Interesse forderte und förderte ${ }^{5}$. Angesichts der unabweisbaren Notwendigkeit, die finanzielle und wirtschaftliche Krise der Welt zu überwinden, hatten politische Fehler Berlins ignoriert oder doch verziehen zu werden, wirkten andererseits die Versuche Frankreichs, Deutschland nicht zuletzt finanziell in Versailler Banden zu halten, zunehmend irritierend und hatten die dabei drohenden oder gemachten Pariser Fehler verhindert oder doch minimiert zu werden.

Daß Deutschland die britische Appeasement-Politik, die sich hier entwickelte, nutzen konnte, lag allerdings auch daran, daß Berlin für deutschbritische und dann für eine Frankreich gemeinsam abgerungene deutschfranzösische Kooperation eine unverzichtbare Voraussetzung lieferte. In Deutschland verschlimmerte sich die finanzielle und wirtschaftliche Situation - beschleunigt durch die Spar- und Deflationspolitik der Regierung Brüning - derart, daß der Reichskanzler endlich die Chance erhielt und zugleich unter den Zwang geriet, sich auf das von ihm für zentral gehaltene Reparationsproblem zu konzentrieren, im Grunde deutsche Außenpolitik auf Reparationspolitik zu reduzieren. Vom Anspruch auf militärische Gleichberechtigung abgesehen, traten andere revisionistische Forderungen vorübergehend in den Hintergrund. Der Verzicht auf die Zollunion wirkte, so spät er ausgesprochen wurde, doch noch rechtzeitig als eine Deklaration des Deutschen Reiches, territoriale Fragen derzeit nicht in Angriff nehmen zu können und nicht in Angriff nehmen zu wollen. Noch während Berliner Minister und Staatssekretäre indigniert erklärten, sich keinesfalls zu dem von Frankreich verlangten politischen Moratorium verstehen zu wollen, kam ein solcher Burgfrieden, was die Regierung anging, temporär und in einem begrenzten Sinne de facto doch zustande.

Diese Atempause hat Frankreich eine bittere Erkenntnis wenigstens etwas versüßt. Kaum war die „Bombe“ Zollunion explodiert, mußten Politiker und Öffentlichkeit nämlich einsehen, daß nicht einmal ein solcher Streich deutscher Revisionspolitik mit der Rückkehr zu der bis 1924 praktizierten Politik der Repressalien und der Okkupationen beantwortet zu werden ver-

5 Zur amerikanischen Haltung in der Reparationsfrage z.B. Außenminister Stimson am 28. 12. 1931; DBFP, Second Scries, Vol. III, Nr. 2. Ferner Simon an Rumbold, 6. 1. 1932, Simon an Lindsay, 16. 1. 1932, Lindsay an Simon, 25. 4. 1932; DBFP, Second Series, Vol. III, Nr. 7, 28, 105. 
mochte. Für eine derartige Rückkehr, so wünschenswert oder sogar notwendig sie manchen Franzosen scheinen mochte, gab es, wie Briand in der Kammer konstatierte, weder eine Möglichkeit noch eine Rechtfertigung. Damals hatte Frankreich mit der Ruhrbesetzung einen gehörigen Beitrag zum wirtschaftlichen und politischen Chaos in Europa geleistet, sich Kritik und Konter der britischen Freunde eingehandelt, das besondere Verhältnis zu Großbritannien beinahe zerstört. Ein zweites Mal durfte man sich ein derartiges Abenteuer nicht leisten, zumal inzwischen mit Dawes-Plan und mit YoungPlan, mit Deutschlands Eintritt in den Völkerbund und mit dem KelloggPakt ein Schutz der deutschen Grenzen geschaffen worden war, den nur kriegerische Handlungen des Reiches aufheben konnten.

Außerdem: Sollte Deutschland etwa in die Arme Italiens getrieben werden? Im Grunde gab es zur Annäherung an den östlichen Nachbarn keine Alternative mehr. Eben deshalb hatte ja die französische Regierung einerseits Deutschland die Zollunion sozusagen abzukaufen versucht und andererseits den wirtschaftlichen wie den politischen Druck in der Angelegenheit - ganz unabhängig von der österreichischen Haltung - auf Wien konzentrieren müssen. Dies alles bedeutete keineswegs, daß es einer französischen Regierung hätte einfallen können, sich offen zu den Kernpunkten der britischen Appeasement-Politik zu bekennen und mit gleicher Gelassenheit die Preisgabe des Reparationsanspruchs an Deutschland ins Auge zu fassen. Doch abgesehen davon, daß Frankreich inzwischen aus wirtschaftlichen Gründen bereit war, über die Höhe deutscher Zahlungen mit sich reden zu lassen, trat doch schon während der Auseinandersetzung um die Zollunion immer deutlicher hervor, daß die französische Regierung, gleich wie sie aussah, keine andere Wahl hatte, als dem britischen Kurs zu folgen - in einigem Abstand und recht zögerlich, da sich naturgemäß viele dagegen sträubten, die Einschränkung der Handlungsfreiheit Frankreichs zuzugeben. Ein Franzose, der zugleich ein guter Kenner Deutschlands war, schrieb 1931: „Seit einem Jahr befindet sich Frankreich Deutschland gegenüber in steter Beunruhigung. Eine Reihe von Kundgebungen hat selbst die Vertrauensvollsten alarmiert und für die Mehrzahl der Franzosen die deutsche Frage noch einmal aufgerollt: die Frage nämlich, ob der Friede mit Deutschland durch Verständigung erlangt werden kann, oder ob er nur durch unsere Macht gesichert ist. Das Mischungsverhältnis, in dem unsere auswärtige Politik seit sieben Jahren gleichzeitig von Rüstung und Versöhnung Gebrauch macht, ihr Wunsch, schrittweise von den alten Sicherungsverfahren zu den neuen der Abkommen und der Annäherung an Deutschland überzugehen, steht wieder einmal zur Diskussion. ,Sind wir zu weit gegangen?' fragen die meisten sich. ,Sollte man nicht noch weiter gehen?` wagen vereinzelte Stimmen sich zu erheben." 6

6 Viénot, Ungewisses Deutschland, S. 84. 
In diesem Stadium der Ungewißheit und der Unsicherheit ging eine gewisse Beruhigung davon aus, daß sich das politische Gespräch zwischen Deutschland und den Westmächten für eine Weile vor allem um die Reparationen drehte und wenigstens die Mitglieder des Berliner Kabinetts nicht mehr so dräuend von Grenzproblemen redeten. Nicht daß die französische Regierung deshalb darauf verzichtet hätte, weiterhin das Versprechen eines zumindest befristeten Berliner Schweigens in Fragen territorrialer Revisionspolitik zu verlangen. Aber das momentane faktische Moratorium trug doch dazu bei, daß zuerst die Unmöglichkeit eines Bruchs mit Deutschland hingenommen wurde und man sich dann nolens volens mit der Möglichkeit eines Einschwenkens auf die britische Linie vertrauter machte. Daß Laval, seit 27. Januar 1931 Ministerpräsident, der Regierung Brüning im September so bereitwillig gegen die deutsche Rechtspresse beistand, war dafür symptomatisch.

Für Italien lagen die Dinge einfacher. Zwar machten Mussolini und Grandi kein Hehl daraus, daß sie die deutsche und vor allem die österreichische Geheimniskrämerei auch persönlich verstimmt hatte ${ }^{7}$, aber ihr Hauptziel bestand in der Verhinderung der Zollunion, und als sie den Eindruck gewannen, daß dieses Ziel erreicht sei oder bald erreicht werde, sahen sie keinen Grund, die vom italienisch-französischen Gegensatz diktierte Annäherung an Deutschland nicht fortzusetzen, zumal die große Abrüstungskonferenz vor der Tür stand, auf der in ihren Augen die Kooperation mit Deutschland unverzichtbar war. Ohne im Konflikt um die Zollunion das Zusammenwirken mit Großbritannien aufzugeben, kehrten sie daher zu der bis zum 18. März verfolgten Politik zurück. Bereits am 8. Mai erging sich der italienische Botschafter in Berlin, Luca Orsini, in den gewohnten „Beschwerden über französische Hegemonialpläne", wie Curtius danach notierte, und er behauptete, Frankreich wolle die deutsch-italienische Zusammenarbeit vereiteln ${ }^{8}$. Und zwei Wochen später, als sie einander bei der 63 . Tagung des Völkerbundsrats in Genf trafen, konferierten Grandi und Schober schon über eine „Kombination", die „es Italien möglich mache, sich Deutschland und Österreich wieder zu nähern". Schober stimmte zu und meinte, es sei „auch das Bestreben Österreichs, etwas zu finden, das eine Erweiterung des deutsch-österreichischen Planes mit sich bringe und Italien

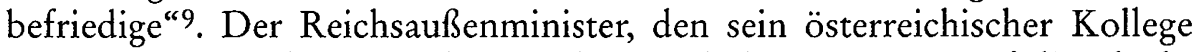
über das Gespräch unterrichtete, scheint Schobers Hinweis auf die Flucht Österreichs aus der Zollunion sogleich verdrängt zu haben, jedoch registrierte er mit Recht, daß die italienische Annäherungsbereitschaft, auf die er und Brüning generell zur Förderung deutscher Revisionspolitik und

7 Aufzeichnung Curtius, 8. 5. 1931; PA, R 29506.

8 Ebenda.

9 Aufzeichnung Curtius, 22. 5. 1931; PA, R 30371/2 k. 
ebenfalls im Hinblick auf die Abrüstungskonferenz großen Wert legten, durch die Zollunion nicht ernstlich gemindert worden war. Noch im Juni ließ Curtius in Rom anfragen, ob der Reichskanzler und er selbst Mussolini willkommen seien. Die Antwort kam umgehend und war positiv10. Am 7./8. August fand der Besuch tatsächlich statt und verlief für beide Seiten sehr zufriedenstellend.

Mussolini sah sicherlich keinen Grund, die Regierung Brüning und das wie man sagen könnte - System Brüning als Bollwerk gegen die radikale deutsche Rechte zu stützen. Auf der anderen Seite ist es doch recht zweifelhaft, ob er damals Hitler und die NS-Bewegung als deutsche Partner vorgezogen hätte. Zwar nahm er es mit Wohlwollen auf, wenn Nationalsozialisten, aus Überzeugung oder als Schmeichelei, gelegentlich kundtaten, er und der italienische Faschismus seien ihre Vorbilder. Auch hatte er zu etlichen NSDAP-Größen persönliche Beziehungen, und mit Giuseppe Renzetti verfügte er über einen Vertrauensmann in der NS-Führung, der ihn nicht nur auf dem laufenden hielt, sondern darüber hinaus einen nicht geringen Einfluß auf Spitzenfunktionäre der NSDAP ausübte ${ }^{11}$. Aber der italienische Faschismus mit seinem Imperialismus war strikt nationalegoistisch orientiert. Bei der Suche nach Verbündeten in anderen Ländern achteten Mussolini und seine Trabanten weniger auf ideologische Verwandtschaft als auf Identität oder doch Parallelität der Interessen ${ }^{12}$. So waren sie zur Zusammenarbeit mit jeder politischen Kraft in Deutschland und mit jeder deutschen Regierung bereit, die den frankreichfreundlichen Kurs, wie ihn Stresemann gesteuert hatte, verließ, den Status quo anzugreifen versprach und damit dem italienischen Imperialismus nützlich sein konnte. Nach anfänglicher Skepsis ${ }^{13}$ hat Mussolini die Regierung Brüning durchaus als schlechten Erben Stresemanns und mithin als brauchbaren Partner betrachtet, dem Italien das Abenteuer mit der Zollunion - sofern diese fiel - schon deshalb verzeihen mußte, weil er nicht wieder auf Stresemannsche Bahnen zurückgeschoben werden durfte. Jedenfalls war ein gutes und den italienischen Zielen dienliches Verhältnis zur Regierung Brüning möglich. Dieses Verhältnis galt es zu pflegen, und solange es gepflegt werden konnte, bestand kein Anlaß, sich die Nationalsozialisten als Herren in Berlin zu wünschen, die im übrigen weder ihre antichristlichen und antikirchlichen Kampagnen noch ihr radikaler Anti-

10 Aufzeichnung Curtius, 26. 6. 1931; ADAP, Serie B, Bd. XVII, Nr. 208. Aufzeichnung Curtius, 9. 7. 1931; PA, R 29506.

11 Hierzu Woller, Machtpolitisches Kalkül.

12 Ebenda.

13 Aufzeichnung Curtius, Ende November 1931, über ein Gespräch mit dem sowjetischen Außenkommissar Litwinow, der ihn über eine Bemerkung des italienischen Außenministers Dino Grandi - gemacht bei dem Zusammentreffen der beiden Außenminister am 24.11. 1930 in Mailand - informierte, daß eine weitere italienisch-deutsche Annäherung nicht denkbar sei, „solange in Deutschland der Stresemann-Kurs weiter verfolgt und eine Annäherung an Frankreich betrieben werde“; PA, R 29449. 
semitismus für eine Allianz empfahlen; schließlich hatte Mussolini im Februar 1929 mit den sogenannten Lateranverträgen seinen Frieden mit dem Vatikan und den Katholiken Italiens gemacht.

In London hingegen hielten viele Politiker die Regierung Brüning nicht nur für kooperationsfähig, sondern für sympathisch und für erhaltenswert. Das lag zwar auch an der guten Wirkung, die der Reichskanzler und Kabinettsmitglieder wie Curtius persönlich auf angelsächsische Gesprächspartner ausübten. Die größere Rolle spielte aber, daß die NS-Bewegung bei britischen Beobachtern tiefstes Unbehagen hervorrief, ein Unbehagen, das seinen Ursprung nicht zuletzt in totalem Unverständnis hatte. Ratlos und äußerst beunruhigt wurden gerade die blinde Begeisterung der Nationalsozialisten, ihre hemmungslose Emotionalität und ihr hoher Erregungsgrad wahrgenommen. Im Mai 1931 schrieb Sir Horace Rumbold: „Ein Angehöriger meines Stabes, der kürzlich eine Großkundgebung in Berlin besuchte, auf der Hitler sprach, berichtet, daß grenzenloser Enthusiasmus gezeigt wurde. Hitler hat dabei nicht mit einem Wort über Politik gesprochen. Er sprach von Selbstdisziplin, Selbstbeherrschung, Opferbereitschaft und donnerte gegen Materialismus, lockere Sitten und laxe Moral. Wie ein amerikanischer Erweckungsprediger riß er 10000 junge Leute zu unbeschreiblichen Ekstasen der Erregung hin." $14 \mathrm{Zu}$ welchen Abenteuern konnten diese jungen Leute nicht verführt werden? Hier wogte eine irrational nationalistische Flutwelle heran, gegen die Deiche gebraucht wurden. Und die Regierung Brüning war in britischen Augen ein solcher Deich.

Anfang März 1931 kam das britische Kabinett überein, Brüning und Curtius nach London einzuladen ${ }^{15}$. Ramsay MacDonald und Henderson hatten keine Verhandlungen im Sinn, nicht einmal - auch wenn es natürlich einen Meinungsaustausch über politische Themen geben mußte - Unterredungen zur Vorklärung konkreter Probleme. Sie wollten lediglich eine Geste machen, die den Deutschen demonstrieren sollte, welches Ansehen Brüning und sein Kabinett außerhalb Deutschlands genossen; so hofften sie, die innenpolitische Stellung der Regierung wenigstens etwas zu stärken ${ }^{16}$. Umgekehrt lehnte es das britische Kabinett ab, dem Reichskanzler Schwierigkeiten zu machen, die es als überflüssig ansah. Anfang Juni sprach der polnische Botschafter in London, Skirmunt, bei Sir Robert Vansittart im Foreign Office vor, um sich über eine eben in Breslau stattgefundene Massenkundgebung des „Stahlhelm“ zu beklagen, auf der - unter Anwesenheit einiger Prominenz, so des Kronprinzen Wilhelm, des Generalobersten Hans v. Seeckt und des Generalobersten Wilhelm Heye, der bis vor kurzem noch als Chef der Heeresleitung amtiert hatte - wilde antipolnische Reden gehalten

14 DBFP, Second Series, Vol. II, Nr. 45.

15 Henderson an Rumbold, 2. 4. 1931; DFBP, Second Series, Vol. II, Nr. 40.

16 Henderson an Rumbold, 21. 4. 1931; DBFP, Second Series, Vol. II, Nr. 42. 
worden waren. Bundesführer Franz Seldte hatte nach einer flammenden Ansprache ausgerufen: „Kameraden, dort ist der deutsche Osten. Dort liegt Deutschlands Zukunft, Deutschlands Schicksal."17 Skirmunt verband seine Klage mit der Bitte an die britische Regierung, Brüning und Curtius bei ihrem Englandbesuch auf derartige Demonstrationen anzusprechen. Sir Robert suchte dem polnischen Botschafter klarzumachen, daß es - abgesehen von der mangelnden Fähigkeit des Kabinetts Brüning, Aktivitäten des „Stahlhelm“ zu unterbinden - nicht tunlich sei, diese deutsche Regierung zu sehr unter Druck zu setzen, weil man dadurch leicht zu ihrem Sturz beitrage, und diese deutsche Regierung sei doch die beste, die man haben könne: Ihr Sturz wäre ein viel größeres Unheil als die Treffen des „Stahlhelm"; "die Alternative sehe so aus, daß sie mich und, wie ich glaubte, jedermann sonst mit wahrem Schrecken erfülle"18.

So hat denn die britische Regierung offensichtlich nicht eine Sekunde lang daran gedacht, die Zollunion anders als eine Torheit zu behandeln und ihretwegen etwa den Besuch der beiden deutschen Politiker abzusagen. Die Einladung blieb bestehen und wurde von Berlin auch unverzüglich angenommen. Die französische Regierung verhielt sich ebenso. Am 11. März von Henderson über die vorgesehene britische Offerte an Brüning informiert, hatte Briand ohne Zögern zugestimmt ${ }^{19}$, und auch nach dem Platzen der Bombe „Zollunion“ gab es keine Pariser Vorstellungen in London, die Deutschen wieder auszuladen. Im Gegenteil. Die französische Regierung fühlte bei der deutschen vor, ob denn auch eine Einladung nach Paris willkommen sei20. Allerdings setzten Laval und Briand darauf, daß es ihnen in Paris möglich sein werde, die deutschen Besucher zum Verzicht auf die Zollunion und vielleicht auch noch zu weiteren Konzessionen zu bewegen. Die Briten wollten jedoch ihre Einladung in erster Linie als von Brüning innenpolitisch verwertbares Zeichen der Freundschaft und der deutschen "Gleichberechtigung“ verstanden wissen, wie Henderson in Berlin bestellen ließ21.

Im Frühjahr 1931 erkannte die Reichsregierung jedoch noch nicht, welch günstige Elemente ins Spiel gekommen waren. Das lag nicht an intellektueller Schwäche. Es lag auch nicht an dem Eindruck, den Frankreichs harter und am Ende erfolgreicher - und von Großbritannien immerhin gestützter - Widerstand gegen die deutsch-österreichische Zollunion machen mußte; im März, April und Mai glaubte man in Berlin noch, das Projekt durchsetzen zu können, niemand hatte schon bemerkt, daß sich, Rußland, Ungarn

17 Dazu der genaue und ziemlich entmutigte Bericht Rumbolds an Henderson, 3. 6. 1931; DBFP, Second Series, Vol. II, Nr. 46.

18 Aufzeichnung Vansittart 3. 6. 1931; DBFP, Second Series, Vol. II, Nr. 48.

19 Henderson an Rumbold, 2. 4. 1931; DBFP, Second Series, Vol. II, Nr. 40.

20 So Brüning am 7.6.1931 in Chequers; DBFP, Second Series, Vol. II, Nr. 51.

21 Henderson an Rumbold, 21. 4. 1931; DBFP, Second Series, Vol. II, Nr. 42. 
und die Türkei ausgenommen, eine europäische Einheitsfront gegen die Union zu bilden begann. Der Grund war vielmehr mentale Befangenheit. Brüning und Pünder, Curtius und Bülow hatten alle ihre politische Vorstellungswelt in den Jahren vor dem großen Krieg entwickelt, in denen die aristokratischen und die akademisch gebildeten bürgerlichen Führungsgruppen des wilhelminischen Deutschland, zu denen sie gehörten, zunehmend zu der Überzeugung gelangt waren, französischer Revanchismus, britischer Handelsneid und der panslawistische Imperialismus des zaristischen Rußland hätten sich zusammengetan, um das aufstrebende und mit Recht seinen „Platz an der Sonne“ fordernde Deutsche Reich wieder niederzuwerfen und für immer am Boden zu halten. Die bewegenden Tage des August 1914, die etwa dem Leutnant der Reserve Hermann Pünder das „Wissen“ einpflanzten, in einen Verteidigungskrieg gegen eine Welt von Feinden zu ziehen ${ }^{22}$, danach das Erlebnis des Krieges, an dem sie dann sämtlich teilnahmen, und die politischen Erfahrungen in den Nachkriegsjahren, die von der ständigen Reibung am Versailler Vertrag bestimmt waren - all dies hat die alte „Einkreisungs"-Psychose am Leben erhalten und bei dem einen oder andern sogar noch verstärkt. Staaten wie Frankreich oder Belgien, bis zu einem gewissen Grade und mit wachsenden Zweifeln auch Großbritannien, galten nach wie vor als gegnerisch. Die Vereinigten Staaten von Amerika waren im Grunde, obwohl Dawes- und Young-Plan die Bekanntschaft mit etlichen hervorragenden Angehörigen ihrer wirtschaftlichen und politischen Eliten vermittelt hatten, noch immer eine unbekannte Größe; beim Blick auf diese unbekannte Größe stellte sich oft der von Präsident Woodrow Wilsons angeblicher Schwäche und Naivität auf der Pariser Friedenskonferenz erstmals geweckte Verdacht ein, die USA seien eine von den Londoner und $\mathrm{Pa}$ riser Politikern leicht zu manipulierende Macht.

Daß unter den gegebenen Umständen Großbritannien und die Vereinigten Staaten - zu gewissen Konditionen auch Frankreich - jetzt im wohlverstandenen eigenen Interesse bereit, ja entschlossen waren, Deutschland zumindest aus seiner wirtschaftlichen Misere zu retten, war ein Faktum, das in der Einkreisungsmentalität verharrende Politiker noch nicht so recht zu erkennen vermochten. Mithin fiel es ebenso schwer, den Willen der Westmächte zur Unterstützung speziell der Regierung Brüning zu bemerken, obwohl der Kanzler und seine Kabinettskollegen den Unterschied zwischen ihren gemäßigten politischen Positionen und dem Radikalismus der Deutschnationalen Hugenbergs wie erst recht der Nationalsozialisten Hitlers allmählich öfter als Argument benutzten, wenn sie sich gegen westliche Kritik an ihrer Politik zu verteidigen suchten und dabei um Sympathie warben. Als Henderson, nachdem die britische Einladung an Brüning und seinen Außenminister ergangen, aber noch kein gleichartiger französischer 
Fühler ausgestreckt worden war, den Deutschen vorschlug, doch auch Paris $\mathrm{zu}$ besuchen, quittierte Curtius die Idee in einer Besprechung mit der kurzen Feststellung, dies „beabsichtige er unter allen Umständen abzulehnen“. Er setzte - offensichtlich brummig und mißtrauisch - hinzu: „Dagegen werde man die Einladung MacDonalds an den Reichskanzler und den AuBenminister, im Frühjahr nach London zu kommen, nicht negativ beantworten können ..., wobei immer noch zu erwägen sein werde, ob auch der Reichskanzler an der Reise teilnehmen müsse. "23 Letzteres ist von Brüning natürlich ignoriert worden, ansonsten fand Curtius jedoch keinen Widerspruch.

$\mathrm{Da}$ also die Deutschland geltenden Absichten der Westmächte nicht rational analysiert, sondern nur spekulativ gedeutet werden konnten - von diesem Urteil sind die exzellenten Diplomaten des Deutschen Reiches auszunehmen, die aber auf die Meinungen und Entscheidungen in Berlin nur geringen Einfluß hatten -, fand sich die als Kabinett der Revisionspolitik angetretene Regierung Brüning im Frühjahr 1931 in einer Art revisionspolitischer Krise. Zwar standen die Ziele unverrückbar fest: Realisierung der territorialen Ansprüche an Polen, quantitative und qualitative Verbesserung des militärischen Instruments, der Reichswehr, ein Ende der Reparationszahlungen und mit all dem die Rückkehr zur Großmachtstellung der Vorkriegszeit. Doch die Wege zu den Zielen lagen nach wie vor im Dunkeln.

Um einige Beispiele für diese Unsicherheit zu nennen: Gegen Ende März hatte Graf Richard Coudenhove-Kalergi, Präsident der Paneuropa-Union, in Paris eine Unterredung mit dem polnischen Außenminister August $\mathrm{Za}$ leski. In dem Bericht über das Treffen, den er Reichskanzler Brüning zukommen ließ, teilte der Graf mit, er habe die Gelegenheit benutzt, Zaleski in der für den europäischen Frieden lebenswichtigen Frage der deutsch-polnischen Beziehungen einen Kompromiß vorzuschlagen: „1. Rückgabe des gesamten Danziger Gebiets an Deutschland. Polen bekommt einen Freihafen in Danzig, wie die Tschechoslowakei in Hamburg. 2. Deutschland erhält eine direkte territoriale Verbindung mit Danzig und Ostpreußen in Gestalt einer Eisenbahnlinie. An der Stelle, an der dieser ,Korridor im Korridor ' die Eisenbahn Warschau - Gdingen schneidet, wird eine der Linien untertunnelt, um keine der beiden Verbindungen zu stören oder zu unterbrechen. 3. Grenzkorrekturen an der gesamten Grenze zur Liquidierung schikanöser Grenzziehungen. Alle polnischen Abtretungen werden an anderen Stellen der Grenze kompensiert, etwa oberschlesische Grenzkorrekturen in Ostpreußen. 4. Entente zwischen Deutschland und Polen mit Einschluß Frankreichs." Er, Coudenhove-Kalergi, habe den bestimmten Eindruck gewonnen, daß dieser „Ausweg“ Zaleski "gangbar erschien“. Bülow kommentierte aufgebracht, solche „außenpolitischen Unterhaltungen des Grafen 
Coudenhove-Kalergi“ seien „für die deutsche Politik durchaus unerwünscht“, da den deutschen Ansprüchen mit der Anwendung von „Palliativ-Mittelchen zur Behebung gewisser besonders auffälliger Mißstände an der Ostgrenze nicht gedient“ sei. Freilich gebe „das Auswärtige Amt sich keinerlei Täuschung über die ungeheuren Schwierigkeiten hin ..., die sich einer etwaigen Lösung der Grenzfrage im deutschen Sinne entgegenstellen"24. Bülow gab den offenbar von Brüning und dessen Umgebung befolgten Rat, dem Präsidenten der Paneuropa-Union künftig die kalte Schulter zu zeigen, jedoch lief sein Kommentar auf das Eingeständnis hinaus, daß die deutschen Forderungen an Polen zwar einen "unversehrlichen Anspruch“ darstellten, wie er sich ein anderes Mal ausdrückte, daß aber für den offensichtlich noch lange währenden Augenblick unklar sei, was zur Verwirklichung getan werden könne. Selbst bei der propagandistischen Verfechtung des Anspruchs hielt Bülow daher noch eine gewisse Zurückhaltung für geboten. Als der polnische Gesandte in Berlin einmal dagegen protestierte, daß das antipolnische Propagandastück „Es brennt an der Grenze“ nicht nur in der Reichshauptstadt, sondern mittlerweile auch in der Provinz aufgeführt werde, notierte Bülow: „In der Tat scheint es mir höchst unerwünscht, daß mit dem Stück ... in unseren Ostprovinzen Propaganda getrieben wird." Und er verlangte nach Mitteln, solch verfrüht aufreizenden Aktivitäten entgegenzuwirken ${ }^{25}$. Auch in dieser Hinsicht hatte sich seit seiner Kritik an der Rede von Minister Treviranus nichts geändert.

Noch weniger klar erschien die Lage in der Abrüstungsfrage. Wohl hielt man es für eine ausgemachte Sache, in absehbarer Zeit irgendwie das Prinzip der militärischen Gleichberechtigung Deutschlands durchsetzen und danach sowohl eine begrenzte Heeresvermehrung - durch Einführung eines die Berufsarmee ergänzenden Milizsystems - wie vor allem eine waffentechnische Modernisierung der Reichswehr vornehmen zu können; kabinettsintern ist schon darüber gesprochen worden, wieviel mehr Geld demnächst für die Anfänge des Ausbaus der Streitkräfte zu einer beweglichen Stoßarmee aufgewandt werden müsse ${ }^{26}$. Doch hieß das Schlüsselwort nach wie vor „irgendwie“. Sollten auf der großen Abrüstungskonferenz, für deren Beginn ja schon der 2. Februar 1932 vorgesehen war, bei der Anmeldung des deutschen Anspruchs auf Gleichberechtigung sofort die deutschen Absichten und Wünsche in ihrer Gesamtheit aufgedeckt und offensiv vertreten werden? Oder sollte Deutschland den Anspruch auf Gleichberechtigung möglichst lange mit dem Verlangen nach der Abrüstung der anderen Staaten verbinden? Wie war zu vermeiden, daß die Abrüstungskonferenz scheiterte, bevor man etwas für die eigenen Ziele erreicht und ehe das an sich er-

26 AdRK, Die Kabinette Brüning, Bd. 2, Nr. 265. 
wünschte Scheitern die eigene rüstungspolitische Handlungsfreiheit eingebracht hatte? Welches Rezept gab es für das taktische Hauptproblem, das darin bestand, Deutschland den Vorwurf zu ersparen, am Scheitern der Konferenz schuld oder mitschuldig zu sein?

Hoesch trat dafür ein, „daß Deutschland bis zum letzten Augenblick von seinen Wünschen nichts erkennen lasse, damit es durch unablässige Betonung unserer Abrüstungsforderungen seinen moralischen Standpunkt bis zuletzt intakt halte"27. Hinter dieser Empfehlung ist unschwer die Hoffnung des Pariser Botschafters zu erkennen, die von ihm vorgeschlagene Taktik werde die deutsche Regierung so lange auf dem eingeschlagenen Weg festhalten, daß sie am Ende nicht mehr umkehren könne und so in der Tat zur allgemeinen Abrüstung beitrage. Bülow hingegen war der Meinung, „man werde schon vor der Konferenz in äußerst vorsichtiger Form ins Gespräch kommen müssen "28; die Reichswehrführung schloß sich dem an ${ }^{29}$, während Brüning hier eine mittlere Position einnahm ${ }^{30}$. Daneben stellte sich neuerdings immer wieder die Frage nach den richtigen Bundesgenossen. War es wirklich angezeigt, sich auf der Konferenz mit den übrigen Revisionisten zu verbünden, von der Sowjetunion über die Türkei und Ungarn bis Italien? Durften sie als stark genug, als zuverlässig genug gelten? Wie war mit Großbritannien und den USA umzugehen? Durfte auf ihre Hilfe gerechnet werden? Mußte Frankreich tatsächlich nur als Gegner behandelt werden? Es war ausgerechnet der anfänglich in frankreichfeindlichen Kategorien gefangene Bülow, der, von Monat zu Monat vorsichtiger werdend und von Monat zu Monat näher an den Kurs wie an die operativen Konzeptionen des früher von ihm herzlich gehaßten Stresemann heranrückend, zu der Ansicht gelangte, daß die militärische Gleichberechtigung des Deutschen Reiches niemals gegen, sondern allein durch eine zumindest partielle Verständigung mit Frankreich erreicht werden könne ${ }^{31}$. Doch blieben alle in solchen Zusammenhängen erörterten Punkte im Frühjahr 1931 noch offen, ohne Entscheidung.

Die schlimmste Verwirrung herrschte jedoch gerade in den Debatten über das zentrale Problem: die Reparationspolitik. Fast jedermann im Deutschen Reich war überzeugt davon, daß Deutschland ein moralisches Recht darauf habe, von der Last der Reparationen endlich befreit zu werden. Die Überzeugung gründete sich auf zwei Annahmen: daß Deutschland, erstens, am Weltkrieg entweder überhaupt nicht schuld oder doch nicht schuldiger gewesen sei als die gegnerischen Staaten, mithin die Rechtfertigung der Reparationen mit der deutschen Verantwortung für den Krieg, wie sie die Pariser

27 Ebenda. Auch Hoesch an Bülow, 16. 1. 1931, 31. 1. 1931; PA, R 29514.

28 AdRK, Die Kabinette Brüning, Bd. 2, Nr. 265.

29 Ebenda.

30 Ebenda.

31 Aufzeichnung Bülow, 12. 7. 1932; PA, R. 29507. 
Friedenskonferenz ausgesprochen hatte, als teils böswillige, teils irrige Siegerwillkür zu gelten habe, jedenfalls als haltlos; das sei von der historischen Forschung - also von der staatlich geförderten und von ihren Editoren und Autoren, auch aus der deutschen Historikerzunft, als nationale Pflichtaufgabe angesehenen und de facto durchweg wissenschaftsfernen Entlastungsliteratur - mittlerweile schlüssig bewiesen worden. Außerdem stehe es, zweitens, fest, daß Deutschland in den Jahren seit Kriegsende eine ungeheure Reparationsleistung bereits erbracht habe, womit es nun genug sein müsse; kaum jemand wollte bemerken, daß die gerade von amtlichen Stellen der Öffentlichkeit präsentierten Berechnungen weite Distanz zu den Realitäten hielten, folglich ihren politisch-argumentativen Zweck allein in Deutschland erfüllen konnten, in Paris und London hingegen nur verärgerten oder amüsierten Spott ernteten ${ }^{32}$. Daneben glaubte, von den Wirtschafts- und Finanzexperten abgesehen, nahezu jedermann im Deutschen Reich felsenfest daran, daß mit dem Ende der Reparationszahlungen sofort die Gesundung aller öffentlichen Haushalte und die Erholung der Wirtschaft einsetzen werde. Von Brünings Zielen ganz unabhängig, begann sich die Reparationsfrage vom zentralen auch zum dringlichsten revisionspolitischen Problem zu entwickeln.

Indes gab es Fragen über Fragen. Wann konnten die Gläubiger mit einem deutschen Angriff auf die Reparationen, also mit einem Angriff auf den immerhin freiwillig unterschriebenen Young-Plan, konfrontiert werden? Mit Aussicht auf Erfolg konfrontiert werden? Noch 1931 oder erst 1932, vor oder nach der Abrüstungskonferenz? Wie war der Angriff zu führen? Konnte die Schlacht mit den Waffen eröffnet werden, die der Young-Plan bot, also mit der Erklärung eines zweijährigen Transfermoratoriums für einen - den sogenannten geschützten - Teil der Annuität? Oder mußte der Young-Plan direkt attackiert, das hieß ganz simpel - wie immer verbrämt die absolute Zahlungsunfähigkeit des Deutschen Reiches behauptet werden? Wie sahen die finanziellen und wirtschaftlichen Folgen aus, wenn die Reichsregierung die Schutzbestimmungen des Young-Plans in Anspruch nahm oder den Plan, weil undurchführbar geworden, einseitig aufkündigte? War nicht in beiden Fällen mit einer Schädigung des deutschen Kredits zu rechnen, die Deutschlands ohnehin krisengeschüttelten Wirtschaft den $\mathrm{Zu}$ sammenbruch bescherte? Noch in der ersten Hälfte des Mai neigte Brüning zu der Auffassung, daß in der Reparationsfrage „eine materielle Änderung“ aufgeschoben werden müsse bis nach der Neuwahl des Präsidenten in den USA (November 1932), den Parlamentswahlen in Frankreich (Mai 1932) und der Abrüstungskonferenz (Ende noch unbekannt) ${ }^{33}$.

32 Zum Reparationsproblem Helbich, Die Reparationen. Ferner Kent, The Spoils of War, und die gründliche Untersuchung von Glashagen, Reparationspolitik.

33 AdRK, Die Kabinette Brüning, Bd. 2, Nr. 291. 
Zur gleichen Zeit waren Kabinettsmitglieder wie Reichsfinanzminister Hermann Dietrich noch keineswegs der Ansicht, daß die Reparationslast sozusagen mit einem Ruck abgeworfen werden könne; er dachte vielmehr an einen Zahlungsaufschub, der durch Ausschöpfung der Möglichkeiten des Young-Plans herauszuschlagen sei $^{34}$. Curtius konstatierte, seine Besprechungen über das Reparationsproblem, die er mit den Botschaftern von Gläubigerländern schon gehabt habe, hätten „nichts Günstiges“ ergeben; nicht zuletzt seien die USA noch nicht in der Lage, sich an Verhandlungen über das Problem der Reparationen und interalliierten Schulden zu beteiligen. In aller Welt rechne man noch mit einer gewissen Dauer des YoungPlans, weshalb reparationspolitische Schritte „einer psychologischen und politischen Vorbereitung im Ausland, insbesondere in den beteiligten Hauptgläubigerländern und den Vereinigten Staaten von Amerika“, bedürften $^{35}$. Finanzminister Dietrich glaubte, daß bei der Verkündung eines Zahlungsaufschubs - die er allerdings erst 1932 für richtig hielt - "die Gefahr des Abziehens kurzfristiger Schulden" nicht hoch zu veranschlagen sei ${ }^{36}$. Reichsbankpräsident Hans Luther war in dieser Hinsicht ganz anderer Meinung und wandte sich generell gegen reparationspolitische Aktivitäten, die nur zur Verschlimmerung der Krise beitragen müßten: „Vielleicht würden wir dann eines Tages nicht mehr in der Lage sein, die erforderlichen Devisen zu beschaffen. " 37 Reichskanzler Brüning hat in der ersten Hälfte des Mai 1931 noch keine klare Entscheidung zwischen den diversen Standpunkten getroffen. Er griff aber den Gedanken seines Außenministers auf, im Ausland Vorbereitungsarbeit zu leisten, und verfügte eine „Erhöhung des Geheimfonds des Auswärtigen Amts ... zum Zwecke einer vermehrten Propaganda" 38 .

Wenn der Kanzler gleichwohl noch im weiteren Verlauf des Mai den Entschluß faßte, die Wirkung der Propaganda nicht abzuwarten und ehebaldigst einen reparationspolitischen Schritt zu tun, der über rhetorische Kritik am Young-Plan hinausging, auch über mehr oder weniger geschickte Erkundigungen bei den Gläubigerstaaten, wie sie denn auf eine deutsche Rebellion gegen den Plan reagieren würden, so lag das keineswegs daran, daß ihm plötzlich ein taktisches Konzept eingefallen wäre oder er die Zeit für reif gehalten hätte. Vielmehr wähnte er sich aus innenpolitischen Gründen in einer Zwangslage. Im Zuge der Deflationspolitik, die er grundsätzlich für richtig und geboten hielt, glaubte er sich genötigt, zur Sicherung eines ausgeglichenen Haushalts schon in nächster Zukunft per Notverordnung neue Gehaltskürzungen und Steuererhöhungen vorzunehmen. Eine solche Maß-

34 Ebenda.

35 Ebenda.

36 Ebenda.

37 Ebenda.

38 Ebenda. 
nahme zu treffen, ohne der Nation ein Äquivalent zu bieten, indem er die Reparationen angriff, schien ihm aber unmöglich, zumal er ja, wie bisher auch, für die Nöte des Reiches und aller Deutschen die Reparationszahlungen als zumindest partiell verantwortlich hinzustellen gedachte. Vor allem war - so Brünings Meinung - ohne eine gleichzeitige Wendung gegen die Reparationen dem Druck der Rechten, der Deutschnationalen und Nationalsozialisten, nicht länger standzuhalten. Die Sicherung der Regierung Brüning und des Systems Brüning verlangte nach einer flankierenden reparationspolitischen Begleitung der kommenden Notverordnung ${ }^{39}$. In dieser Phase erzwang also nicht die Reparationspolitik einen deflationspolitischen, sondern umgekehrt die Deflationspolitik einen reparationspolitischen Akt.

Indes vermochte Brüning immer noch keine Möglichkeit zu entdecken, die Reparationen im Rahmen des Young-Plans oder durch Kündigung des Plans anzugehen. Frankreich und die französischen Trabanten wie Belgien und die Tschechoslowakei würden sich widersetzen und dabei vermutlich die Unterstützung Großbritanniens und der USA finden. Aus Rom waren zwar gelegentlich süß klingende Worte zu vernehmen. Wie würde aber Mussolini reagieren, wenn tatsächlich Millionen nicht in die italienischen Kassen fließen sollten, die im Etat fest eingeplant waren? Im übrigen nützte das Wohlwollen bloß des schwachen Italien ohnehin wenig. Erst bei der Suche nach einem Ausweg aus diesem Dilemma bildete der Kanzler jene reparationspolitische Taktik aus, an der er dann bis zum Ende seiner Amtszeit zäh festhielt. Inzwischen war der Beginn des Besuchs von Brüning und Curtius in England, der ursprünglich für Anfang Mai vorgesehen gewesen war, auf den 5. Juni festgelegt worden. Brüning beschloß nun - mit Zustimmung seines Kabinetts -, die bis dahin fertige und von Reichspräsident v. Hindenburg unterzeichnete Notverordnung parallel zum Eintreffen in England zu veröffentlichen, zugleich einen Aufruf der Reichsregierung an die Deutschen zu erlassen, in dem zu konstatieren sei, daß Deutschland die Last der Reparationen nicht länger zu tragen vermöge ${ }^{40}$. In der Tat lauteten die reparationspolitischen Kernsätze des von Reichsfinanzminister Dietrich nach Brünings Instruktionen formulierten Aufrufs: „Wir haben alles angespannt, um unseren Verpflichtungen aus dem verlorenen Kriege nachzukommen. Auch ausländische Hilfe haben wir hierfür in weitem Maße in Anspruch genommen. Das ist nicht mehr möglich. Die Einsetzung der letzten Kräfte und Reserven aller Bevölkerungskreise gibt der deutschen Regierung das Recht und macht es ihr dem eigenen Volke gegenüber zur Pflicht, vor der Welt auszusprechen: Die Grenze dessen, was wir unserem Volke an Entbehrungen aufzuerlegen vermögen, ist erreicht! Die Voraussetzungen, unter denen der neue Plan [Young-Plan] zustande gekommen ist, haben sich 
durch die Entwicklung, die die Welt genommen hat, als irrig erwiesen. Die Erleichterung, die der neue Plan nach der Absicht aller Beteiligten dem deutschen Volke bringen sollte und fürs erste auch zu bringen versprach, hat er nicht gebracht. Die Regierung ist sich bewußt, daß die aufs äußerste bedrohte wirtschaftliche und finanzielle Lage des Reiches gebieterisch zur Entlastung Deutschlands von untragbaren Reparationsverpflichtungen zwingt. Auch die wirtschaftliche Gesundung der Welt ist hierdurch mitbedingt." 41

Eine wahrhaft ingeniöse Erklärung. Der deutschen Bevölkerung verhieß der Aufruf scheinbar unzweideutig die Eröffnung des Feldzugs gegen die Reparationen. Auf der anderen Seite vermied er mit Bedacht die Ankündigung des Transferaufschubs und erst recht die Aufkündigung des YoungPlans. Paris, London und Washington wurde lediglich eine Bestandsaufnahme der finanziellen und wirtschaftlichen Lage des Reiches präsentiert; daraus die richtigen Schlüsse zu ziehen und das Erforderliche zu veranlassen, sollte den dort amtierenden Regierungen überlassen bleiben, ja nun als deren Pflicht erscheinen. Mit einem Streich - und ohne Deutschland formal dem Vorwurf der Vertragsverletzung auszusetzen - gedachte Brüning die Verantwortung für die deutsche Wirtschaft und die internationale wirtschaftliche Situation den Gläubigerstaaten zuzuschieben. Mit anderen Worten: Hatte der Kanzler die deutsche und die globale Wirtschaftskrise bislang ganz simpel als notwendige Voraussetzung erfolgreicher deutscher Reparationspolitik angesehen, so begann er die Krise jetzt zu instrumentalisieren, und zwar auf eine Weise, mit der er Deutschland das irritierende Drängen auf Rettungsmaßnahmen ersparen, dem Schuldner vielmehr die Rolle eines gleichsam aufgedrängte Hilfe Annehmenden sichern wollte. Brünings Erinnerungen sind für die Rekonstruktion faktischer Abläufe nur von geringem Wert, doch gibt er in ihnen die Grundtendenzen seiner Politik und die in bestimmten Phasen gewählte taktische Marschroute durchaus zuverlässig wieder. Wenn er schrieb: „Aus der Krankheit konnten wir unsere Waffe machen!“', so charakterisierte er treffend sein Konzept im Frühsommer $1931^{42}$. Dabei wußte der gewiegte Finanzexperte - im Gegensatz zu seinem Finanzminister - sehr genau, daß der von Dietrich offenbar recht leichtherzig formulierte Aufruf außerhalb Deutschlands als Bankrotterklärung des Deutschen Reiches aufgefaßt werden und mindestens eine neue Welle von Abzügen kurzfristiger Kredite anstoßen mußte ${ }^{43}$. Daß dies die - ihm sehr wohl

41 Schulthess', 1931, S. 120 f.

42 Brüning, Memoiren, S. 309.

43 An Warnungen hatte es nicht gefehlt, so vom Generalkonsul in New York Otto Kiep bereits am 11. 9. 1930 (PA, R 80147), und am 13. 4. 1931 hatte Botschafter v. Prittwitz die Auffassung von Roland W. Boyden, einem Berater der amerikanischen Regierung in europäischen Angelegenheiten, mitgeteilt, Deutschland müsse alles vermeiden, was seinen politischen und wirtschaftlichen Kredit „aufs ernsteste“ gefährden würde, etwa eine „unverhoffte Moratoriumserklärung“; PA, R 80147. 
bewußte - wirtschaftsschädliche Wirkung der neuen Notverordnung nur potenzieren konnte, stand ihm gewiß ebenfalls vor Augen. Aber wenn der Kranke noch um einiges kränker wurde, so paßte das exakt zu der nun verfolgten Taktik.

Der Erfolg übertraf die kühnsten Erwartungen. Den ersten hohen Punktgewinn heimsten Brüning und Curtius bereits bei ihrem Besuch in England ein. Brüning fürchtete noch bei Antritt der Reise, daß die Briten vor allem über die Abrüstung reden wollten und er womöglich vor der unangenehmen Alternative stehen werde, entweder den militärischen Interessen des Reiches widersprechende Festlegungen - im Blick auf die kommende Abrüstungskonferenz - einzugehen oder seine Gastgeber zu verärgern ${ }^{44}$. Die Absichten, von denen die britische Einladung bestimmt worden war, gröblich verkennend, hegte wiederum der Reichsaußenminister die verwegene Hoffnung, das gesamte revisionistische Programm Deutschlands, einschließlich der Forderung nach Rückgabe der Kolonien, darlegen und für die deutschen Ansprüche britisches Verständnis wecken zu können ${ }^{45}$. Indes war der Kanzler zugleich entschlossen, das Treffen für eine gründliche Erörterung des Reparationsproblems zu nutzen, und zum nicht geringen Erstaunen der beiden deutschen Gäste war eine solche Debatte genau das, worauf sich die vom Berliner Botschafter Großbritanniens gut vorbereiteten englischen Gesprächspartner eingestellt hatten, ja was diese - die ihrem ursprünglichen Einladungsmotiv also inzwischen ein zweites hinzugefügt hatten - in der Tat selbst wollten ${ }^{46}$.

So konnten Brüning und Curtius in den Tagen vom 5. bis zum 9. Juni, erst in London, dann in Chequers, dem Landsitz des britischen Premierministers, die gerade erlassene Notverordnung erläutern und damit den rücksichtslosen Sparwillen der Reichsregierung - wie ihre Treue zum YoungPlan - beweisen, anschließend die deutschen Schwierigkeiten mit den Reparationen dartun, und das ganz im Geiste des die Notverordnung begleitenden Aufrufs. Premierminister McDonald, Außenminister Henderson, Sir Robert Vansittart, der Staatssekretär im Foreign Office, Sir Frederick LeithRoss, der wirtschaftliche Chefberater der britischen Regierung, und Montagu Norman, Leiter der Bank von England, waren tief beeindruckt, zumal Brüning, wie stets im Verkehr mit Repräsentanten anderer Staaten, wohl mit großem Ernst, jedoch zurückhaltend und ruhig sprach, dem Anschein nach einfach Fakten ausbreitend. Es entstand eine Atmosphäre, die einer guten Aufnahme deutscher Argumente sehr förderlich war.

Zwar zeigte sich Henderson noch recht kritisch, als Brüning immerhin erklärte, daß Deutschland vielleicht im November des Jahres die Schutz-

44 AdRK, Die Kabinette Brüning, Bd. 2, Nr. 324.

45 Aufzeichnung Curtius, 10. 6. 1931; PA, R 28299.

46 Rumbold an Henderson, 1. 5. 1931; DBFP, Second Series, Vol. II, Nr. 43. 
klauseln des Young-Plans in Anspruch nehmen müsse ${ }^{47}$, und Sir Frederick Leith-Ross meinte im Laufe der Unterhaltungen einmal, ein direkter Versuch zur Revision des Young-Plans sei derzeit äußerst schwierig und gefährlich ${ }^{48}$. Sir Robert Vansittart wies darauf hin, daß mit den Vereinigten Staaten bestimmt erst nach den Präsidentschaftswahlen vom November 1932 über die Reparationen geredet werden könne; Sir Robert merkte außerdem vorwurfsvoll an, manche Aktionen der deutschen Regierung seien nicht geeignet, ausländische Investoren zu langfristigen Anleihen zu ermutigen $^{49}$. Auch kam es zu einer kleinen Krise der Gespräche, als am 6. Juni Sir Ronald Lindsay aus Washington telegrafisch mitteilte, welch verheerenden Eindruck der Aufruf der Reichsregierung in den USA gemacht und dort dem Kredit Deutschlands ernstlich geschadet habe ${ }^{50}$. Sir Robert Vansittart wurde gebeten, die Telegramme wörtlich vorzulesen, und da die anwesenden Briten den Text des Aufrufs offenbar erst jetzt richtig zur Kenntnis nahmen und anscheinend einen Moment lang glaubten, schon die Kündigung des Young-Plans zu hören, kühlte die Stimmung vorübergehend ab, hatte doch Henderson zu Beginn betont, die Reparationsfrage könne, so groß die Schwierigkeiten Deutschlands seien, nicht durch einseitiges deutsches Handeln, sondern nur durch internationale Anstrengungen gelöst werden. Selbst der ansonsten mit seinen deutschen Kollegen ausgezeichnet zusammenarbeitende Montagu Norman, der den Wortlaut des Aufrufs bis dahin noch nicht gekannt hatte, äußerte sich entsetzt, brachte sein Verständnis für die amerikanischen Reaktionen zum Ausdruck, konstatierte eine völlige Veränderung der Situation und sagte, er hoffe sehr, daß die deutsche Regierung nicht noch mehr derartige Überraschungen auf Lager habe; Curtius erwiderte - trocken oder naiv? -, „derzeit seien keine weiteren Manifeste in Vorbereitung" 51 .

Aber der Sturm ging schnell vorbei, und zwar vor allem deshalb, weil die britischen Politiker, also MacDonald und Henderson, die Nachrichten aus Washington bezeichnenderweise recht gleichmütig aufnahmen und in der Diskussion mit den deutschen Gästen nicht weiter darauf zurückkamen. Offensichtlich war ihnen nicht entgangen, daß der amerikanische Außenminister Henry L. Stimson, obwohl ihm der Aufruf der Reichsregierung tatsächlich wie eine deutsche Moratoriums-Erklärung klang und er einen Abzug kurzfristig in Deutschland angelegter Gelder prophezeite, der den Vorgängen im Herbst des Vorjahres nicht nachstehen werde, in der Sache

47 Summary of the Discussion with the German Ministers at Chequers on Sunday, June 7, 1931; DBFP, Second Series, Vol. II, Nr. 51.

48 Ebenda.

49 Ebenda.

50 Lindsay an Henderson, 6. 6. 1931; DBFP, Second Series, Vol. II, Nr. 49, 50.

51 Summary of the Discussion with the German Ministers, June 7; DBFP, Second Series, Vol. II, Nr. 51. 
selbst auffallend milde blieb. „Der Ernst der deutschen Situation“, so sagte er laut Lindsay, „war auch ohne eine derart unselige Kundmachung evident genug, um die Notwendigkeit sorgfältiger Prüfung deutlich zu machen."52 Und zum Moratorium bemerkte er lediglich, wenn schon ein solches erklärt werde, dann sollte es auf eine Art und Weise geschehen, die ganz klar besage, daß es allein um die Reparationen gehe, nicht hingegen um kommerzielle Schulden ${ }^{53}$. Die britischen Gastgeber nahmen Stimsons Äußerungen um so befriedigter zur Kenntnis, als ihre wahre Meinung ja nicht in den kritischen Sätzen an die Adresse Brünings und seines Außenministers zum Ausdruck kam; damit wollte man im Grunde die Deutschen nur zu einem vorsichtigen und mit den an die USA verschuldeten europäischen Gläubigerstaaten abgestimmten Vorgehen anhalten.

Was die Briten wirklich im Auge hatten, durften Brüning und Curtius anderen Bemerkungen entnehmen. So war es gerade Henderson, der Vansittarts Behauptung widersprach, die Vereinigten Staaten seien für Verhandlungen über die Reparationen noch nicht reif: Die Ansichten in den USA veränderten sich, sagte der britische Außenminister und zitierte eine Rede des Senators William E. Borah, in der dieser die Streichung von Regierungsschulden vorgeschlagen habe; Henderon setzte hinzu, die Lage in Europa sei ernst und man müsse ihr begegnen ${ }^{54}$. Andeutungsweise lag damit das britische Programm auf dem Tisch: zunächst eine für die Schuldner größtmögliche Erleichterung bringende und andererseits für die Gläubiger - vornehmlich Frankreich - akzeptable Lösung des Reparationsproblems in Europa, danach Liquidierung der alliierten Schulden an die USA. Der Gouverneur der Bank von England, Montagu Norman, der zu den Gesprächen erst später hinzukam, eröffnete seine Diskussionsbeiträge mit der frohgemuten - jedenfalls nicht den geringsten Schrecken verratenden - Frage, er nehme an, die Deutschen seien gekommen, um zu erklären, daß sie nicht länger Reparationen zahlen könnten ${ }^{55}$. Brüning und Curtius bestritten das: Selbstverständlich werde Deutschland den Young-Plan erfüllen, solange das möglich sei; es gehe ihnen einfach darum, die Schwierigkeiten darzulegen und aus Loyalität zu ihren britischen Kollegen darauf aufmerksam zu machen, daß die Zeit komme, wo sie bei den Sicherungen des Plans Zuflucht suchen müßten ${ }^{56}$. Daß Montagu Norman dies mit den Worten quittierte, Brüning und Curtius hätten fraglos den Weg in die Zukunft vorzubereiten, konnte auf die Deutschen nicht entmutigend wirken, wenngleich Norman im weiteren keinen Zweifel daran ließ, daß er die Finanzkrise in Österreich und

52 Lindsay an Henderson, 6. 6. 1931; DBFP, Second Series, Vol. II, Nr. 49.

53 Lindsay an Henderson, 6. 6. 1931; DBFP, Second Series, Vol. II, Nr. 50.

54 Summary of the Discussion with the German Ministers, June 7; DBFP, Second Series, Vol. II, Nr. 51.

55 Ebenda.

56 Ebenda. 
Ungarn für vordringlich halte und den Deutschen empfehle, ihren Problemen noch eine Weile mit eigenen Mitteln zu Leibe zu rücken ${ }^{57}$. Auch das zum Abschluß des Treffens veröffentlichte Kommuniqué, verfaßt von Curtius und Botschafter v. Neurath zusammen mit Sir Robert Vansittart und Sir Frederick Leith-Ross, enthielt nicht einen Satz, der als Mahnung an die Reichsregierung zu deuten gewesen wäre, den Young-Plan nicht anzutasten.

Obwohl sie noch immer nicht richtig erkannten, wie weit die Briten bereits zu gehen bereit waren, sagten sich Brüning und Curtius mit Recht, daß sie einen großen Erfolg verzeichnen durften. Mit verständlicher Zufriedenheit notierte der Reichsaußenminister am Tag der Rückkehr aus England, am 10. Juni, Brüning und er hätten in Chequers die finanzielle Lage Deutschlands dargelegt, also einen Gläubigerstaat unterrichtet: „Wenn wir in der Folge zu autonomen Maßnahmen schreiten, so wird uns kein Vorwurf gemacht werden können. "58 Drei Tage später schrieb er noch deutlicher und freudiger an Neurath: In Chequers sei „wiederholt klar ausgesprochen [worden], daß die deutsche Regierung die Erklärung eines Aufschubs nach dem Youngplan für allernächste Zeit in Aussicht nehmen müsse“. Die englischen Minister hätten das zur Kenntnis genommen, zwar ohne zuzustimmen, aber auch ohne zu protestieren. Die Reparationsfrage sei mithin „in der politischen Weltöffentlichkeit zur erneuten Diskussion gestellt ..., ohne daß es dabei zu politischen Komplikationen gekommen wäre. Damit ist ein psychologisch kritischer Punkt ohne politischen Rückschlag überwunden worden." 59 Brüning war im übrigen nicht zuletzt deshalb erleichtert, weil Curtius einen Versuch Vansittarts, den Gedanken einer langfristigen Anleihe wieder ins Spiel zu bringen, mit der kurzen Bemerkung abgeblockt hatte, das sei eine abgetane Sache; Deutschland habe weder den Wunsch noch die Fähigkeit, seine Probleme auf solche Art zu lösen ${ }^{60}$.

Ein Haken war freilich bei all dem. Mit der Warnung, Deutschland werde demnächst den vom Young-Plan vorgesehenen Transferaufschub beantragen müssen, hatten sich Brüning und Curtius praktisch darauf festgelegt, daß die Reichsregierung nur im Rahmen des Young-Plans und nicht direkt gegen den Plan handeln werde. Das war in doppelter Hinsicht unangenehm. Erstens herrschte in dieser Frage noch keineswegs Einigkeit im Kabinett und unter den sonst mit dem Reparationsproblem befaßten deutschen Fachleuten. Zweitens - und vor allem - waren die Schutzmechanismen des Plans nicht nur zum Schutz des Schuldnerstaates konstruiert worden, sondern zugleich zum Schutz des Plans. Der Transferaufschub war eben bloß ein Aufschub. Nach Ablauf der Frist mußten die Zahlungen wieder aufgenommen

57 Ebenda.

58 Aufzeichnung Curtius, 10. 6. 1931; PA, R 28229.

59 Curtius an Neurath, 13.6. 1931; PA, R 28229.

60 Summary of the Discussion with the German Ministers, June 7; DBFP, Second Series, Vol. II, Nr. 51. 
und die gestundeten Gelder - verzinst - nachgezahlt werden. Auch durfte der Aufschub höchstens zwei Jahre dauern. Nach relativ kurzer Zeit war also nicht allein wieder die gewohnte, sondern eine vermehrte Last zu schultern. Im übrigen lief ja während der Zeit, da die Bestimmungen des Plans in Anspruch genommen wurden, die Zahlung der ungeschützten Annuität weiter.

Wie angesichts dieser Rechtslage die Mechanismen des Young-Plans zu Waffen gegen den Plan umgeschmiedet werden sollten, war nicht recht zu sehen. Nun stand der Regierung Brüning jedoch vor Augen, eine Abmachung über „eine Atempause von etwa drei Jahren“ zu erreichen, wie sich Staatssekretär v. Bülow in den Tagen von Chequers ausdrückte, „ein längeres Feierjahr für alle internationalen Zahlungen, die auf Grund der Kriegsliquidation erfolgen" 61 ; danach sollte das Reparationskapitel natürlich endgültig abgeschlossen werden. Konnte das mit dem „Druckmittel YoungMoratorium" England abgehandelt und Frankreich abgetrotzt werden? AuBerdem verstand Bülow - nicht anders als Brüning - die Reparationen mit Recht nur als ein Teilproblem aller internationalen Zahlungen, die auf den Weltkrieg zurückgingen. Wenn die USA weiterhin auf der Eintreibung der alliierten Kriegsschulden bestanden, würden Frankreich und auch Großbritannien auf deutsche Reparationen gar nicht verzichten können. Und hatten nicht Montagu Norman und Sir Robert Vansittart die amerikanische Verhandlungsbereitschaft für 1931 und 1932 - das heißt auch für den November 1931, den Brüning als letztmöglichen Termin eines deutschen Antrags auf Transferaufschub bezeichnet hatte - sehr skeptisch beurteilt? Chequers war ein Erfolg, aber es hingen so dichte Nebelschwaden über der politischen Landschaft, daß man den weiteren Weg noch immer nicht so recht zu erkennen vermochte.

Den nächsten Fortschritt brachte denn auch nicht eine Aktion der Reichsregierung, sondern ausgerechnet ein Schritt der für handlungsunfähig gehaltenen amerikanischen Regierung, der freilich unmittelbar auf eine von der Reichsregierung geschaffene Situation zurückging. Die Kritiker innerhalb und außerhalb Deutschlands, die als Folge des von Finanzminister Dietrich verfaßten Aufrufs vom 5. Juni - nicht als Folge der Notverordnung vom gleichen Tage - eine neue Welle der Abzüge kurzfristiger Kredite erwarteten, sahen sich in einem Maße bestätigt, das wohl die Befürchtungen der meisten noch übertraf. Die Kündigungswelle, die von der Bankrotterklärung der Reichsregierung ausgelöst wurde, kostete die deutsche Wirtschaft im Laufe weniger Wochen rund 3 Milliarden Reichsmark und ließ den Devisen- und Goldbestand der Reichsbank auf einen beängstigenden Tiefstand sinken ${ }^{62}$. Der Schlag traf die deutschen Finanzen und die deutsche

61 Bülow an Hoesch, 8. 6. 1931; PA, R 29506.

62 Keese, Die volkswirtschaftlichen Gesamtgrößen, S. $69 \mathrm{ff}$. 
Wirtschaft um so wuchtiger, als die nach den Septemberwahlen von 1930 erlittenen Verluste inzwischen durch neu hereinströmende oder zurückflieBende Gelder wohl zum Teil ausgeglichen worden waren, aber eben nur zum Teil; die neuerliche Katastrophe also erschütterte einen Organismus, dessen Konstitution weit schwächer war als im Herbst 1930. Der wirtschaftliche Kollaps Deutschlands begann sich abzuzeichnen, und es lag auf der Hand, daß, sollte es tatsächlich zu diesem Kollaps kommen, der deutsche Zusammenbruch die Finanzkrise in Österreich und mittlerweile auch in Ungarn unheilbar machen, damit einen über den ganzen Kontinent hinwegrasenden Flächenbrand entfachen mußte. Wie sehr das die tiefe Krise verschlimmern würde, in der die Weltwirtschaft ohnehin steckte, war gar nicht auszudenken.

Eine innerdeutsche - für die Außenwelt allerdings ebenfalls gefährliche Konsequenz stellte sich ohnehin ein. Die Ende Juni 1931 einsetzende und den ganzen Juli währende deutsche Bankenkrise, die etliche deutsche Großbanken, so die Dresdner, in derartige Abgründe der Illiquidität stieß, daß sie nur durch eine fast schon auf Verstaatlichung hinauslaufende Intervention des Reiches gerettet werden konnten, hing zwar nicht unmittelbar mit der Kündigungswelle zusammen, die dem Aufruf vom 5. Juni zu danken war. Vielmehr ist der Grund der Bankenkrise darin zu suchen, daß bedeutende deutsche Unternehmen in immer größere Absatzschwierigkeiten gerieten, zahlungsunfähig wurden und dann die Banken, von denen sie über jedes wirtschaftlich vertretbare Maß hinaus mit Krediten gestützt worden waren, in die Strudel der eigenen Pleite zogen; so verlor die Darmstädter und $\mathrm{Na}$ tionalbank (Danat) beim Bankrott der Norddeutschen Wollkämmerei und Kammgarnspinnerei (Nordwolle) mehr als ihr Eigenkapital63. Doch wäre es der Reichsregierung, der Reichsbank und dem ganzen deutschen Bankensystem ohne den zuvor erlittenen Aderlaß vielleicht möglich gewesen, mit der Julikrise aus eigener Kraft fertig zu werden. Wie die Dinge lagen, konnte das nicht gelingen. Hätten die Zentralbanken der "Gegnerstaaten“, wie sich Mitglieder des Kabinetts gerne ausdrückten, nicht hilfreich eingegriffen, wäre die Regierung Brüning wahrscheinlich schon im Sommer 1931 untergegangen - nicht ohne eigenes Zutun.

In jenen Staaten, in denen wirtschaftliche Gesichtspunkte besonderes Gewicht besaßen, also namentlich in Großbritannien und den USA, ist die Entwicklung in Deutschland mit wachsender Sorge beobachtet worden. Daß die schwächer und schwächer pulsierende eigene Wirtschaft unter der deutschen Krise zu leiden haben werde, konnte niemand mehr übersehen. Außerdem hatten britische und amerikanische Investoren viel Geld in Deutschland angelegt, das als äußerst gefährdet erscheinen mußte. Beides verlangte nun nach schützender Aktivität der Regierungen. Eine Woche

63 James, The German Slump, S. $283 \mathrm{ff}$. 
nach Brünings und Curtius' Abreise aus England schrieb der britische Botschafter in Paris, Lord William Tyrrell, an Außenminister Henderson, die französische Regierung habe „etwas beunruhigende Nachrichten“ über die finanzielle Situation in Deutschland; Lord Tyrrell fügte die Überlegung hinzu, daß, falls die Abzüge von der Reichsbank in großem Maßstab anhalten sollten, eine Zahlungsunterbrechung notwendig werden könnte ${ }^{64}$. Henderson antwortete umgehend, die Lage in Deutschland sei in der Tat außerordentlich kritisch, kritischer als irgendwann in den vergangenen sechs Jahren. Falls sich deutsches Kapital der Abzugsbewegung ausländischer Kredite anschließe, drohe der Zusammenbruch der Mark. Er sprach unumwunden aus, daß man vor einer Einstellung der Reparationszahlungen stehen könne, darüber hinaus aber vor „einem finanziellen Kollaps in Deutschland und Österreich, der das ernste Risiko politischer und sozialer Unruhen in diesen Ländern heraufbeschwört, mit Rückwirkungen auf das übrige Europa"65. Den Schlüssel zur Lage hielten die Vereinigten Staaten und Frankreich in Händen. Henderson schloß: „Wir hoffen, daß die französische Regierung die Situation vollständig erfaßt.“

Lord Tyrrell gab die Mahnung an die Pariser Regierung weiter, doch war es für Appelle an die französische Vernunft noch um einge Wochen zu früh, zumal Frankreich auf Grund seiner Wirtschaftsstruktur noch viel weniger als mittlerweile alle anderen Staaten unter der Krise zu leiden hatte und sich eines ständigen Zustroms von Gold erfreute; britische Politiker und Finanziers charakterisierten letzteres verärgert als mißbräuchliche Ausnutzung der wirtschaftlichen Position Frankreichs, doch änderte das nichts daran, daß die Pariser Regierung im Moment noch - im trügerischen Gefühl eigener Sicherheit - dazu neigte, die Verschärfung der Krise in Deutschland und deren Auswirkung auf Großbritannien und die Vereinigten Staaten mit dort erst recht ungnädig aufgenommener Gelassenheit zu betrachten. Die französischen Politiker verstanden die finanziellen und wirtschaftlichen Nöte Österreichs und auch Ungarns sehr viel besser, weil bei der Gewährung der von Wien und Budapest erbetenen Finanzhilfe sogleich politische Forderungen durchgesetzt werden konnten. War es im Falle Österreichs der Verzicht auf die Zollunion mit Deutschland, so wurde der ungarischen Regierung ein längerer Wunschzettel präsentiert: 1 . Schaffung einer freundschaftlichen Atmosphäre zu Frankreich und den Staaten der Kleinen Entente, damit verbunden Einschränkung der revisionistischen Propaganda, 2. Abschluß eines Handelsvertrags mit der Tschechoslowakei, 3. Sanierung des Haushalts, insbesondere durch Reduzierung der militärischen Ausgaben, 4. Aufhebung der paramilitärischen Verbände. Insgesamt lief das auf Aus-

${ }^{64}$ Henderson an Lord Tyrrell, 15. 6. 1931; DBFP, Second Series, Vol. II, Nr. 55; das Telegramm Lord Tyrrells vom 13.6. 1931 in Anm. 1 zum Schreiben Hendersons.

65 Ebenda. 
söhnung Ungarns mit dem Status quo hinaus. An den Rand eines Berichts, in dem die Budapester Gesandtschaft des Reiches mitteilte, Frankreich stelle solche Ansprüche an Ungarn, schrieb Ministerialdirektor Köpke: „Simile für Deutschland"!66

Da Ungarn bei der Suche nach Unterstützung vergeblich in London und Rom anklopfte, wandte es sich schließlich notgedrungen an Paris. Tatsächlich kam im Sommer 1931 eine französisch-ungarische Verständigung zustande, die, obwohl beide Seiten beteuerten, politische Bedingungen für die Pariser Finanzhilfe seien weder genannt noch akzeptiert worden, auf eine partielle Annahme der französischen Forderungen hinauslief. Nachdem Ministerpräsident Graf Stefan Bethlen am 19. August zurückgetreten und von einem Kabinett unter Graf Julius Karolyi abgelöst worden war, wurden im Etat in der Tat Berichtigungen zu Lasten der Armee vorgenommen ${ }^{67}$. Und nicht nur das. War in den öffentlichen Bekundungen der Regierung Bethlen Ungarns flammender Protest gegen die von den Pariser Friedensmachern erzwungenen Gebietsverluste schon förmlich ritualisiert gewesen, ebenso die Betonung der Notwendigkeit enger Beziehungen zu Deutschland und Italien, so sprach Graf Karolyi in seiner Antrittsrede zwar durchaus noch davon, daß das Freundschaftsverhältnis zu Italien ausgebaut und die guten Beziehungen zu Deutschland wie bislang gepflegt werden müßten, doch betonte er dann seine Freude darüber, daß „unsere Beziehungen zu Frankreich sich andauernd verbessern und uns von französischer Seite herzliches Verständnis und Freundschaft bezeigt wird“. Die „Revision der Trianongrenzen" blieb unerwähnt ${ }^{68}$.

Ungarn schien auf dem Weg zur Anerkennung des Status quo immerhin den ersten Schritt getan zu haben. Jedoch sollten in späteren Jahren gerade die Ungarn zum klassischen Beispiel dafür werden, daß einer Nation eine außenpolitische Programmatik, die Gemüter und Sinne bewegt, nicht abgekauft werden kann. Bereits im Sommer 1931 lieferte Ungarn Belege dafür, $\mathrm{da} ß$ die freundlichen Worte an die Adresse Frankreichs lediglich als Ergebnis einer momentanen $Z$ wangslage gedeutet werden durften. Abgesehen davon, daß Graf Karolyis nach wie vor einflußreicher Vorgänger Graf Bethlen wie stets die Wendung „Errichtung des alten Großungarn“ gebrauchte, und zwar mit Sehnsucht in der Stimme ${ }^{69}$, gehörte dem neuen Kabinett als Wehrminister - und in dieser Eigenschaft keine schwache Figur - Julius Gömbös an, ein in der Wolle gefärbter ungarischer Nationalist und Revisionist, der seit den frühen zwanziger Jahren engste Verbindung zu den Führern rechtsextremistischer Organisationen in Deutschland hielt, einschließlich der NSDAP; zwölf Jahre vor Mussolini, nämlich 1924, prägte Gömbös den Be-

66 Schlimpert an AA, 26. 8. 1931; PA, R 74142.

67 Ebenda.

68 Schlimpert an AA, 25. 8. 1931; PA, R 74142.

69 Ebenda. 
griff „Achse Berlin - Rom“, die dereinst das Schicksal Europas - natürlich mit Profit für Ungarn - entscheiden werde ${ }^{70}$. Die deutsche Gesandtschaft kommentierte denn auch, Gömbös dürfe als sichere Stütze des bisherigen Kurses gelten: „Seine Verehrung für den Faschismus und sein Streben, mit der deutschen Wehrmacht in enger Fühlung zu stehen, sind eingeweihten Kreisen ebenso bekannt, wie seine ausgesprochene Abneigung gegen Frankreich und besonders die Kleine Entente. Mit seinem Bleiben werden alle Gerüchte einer bedingungslosen französischen Orientierung dementiert."71 Die Wirksamkeit des von Frankreich praktizierten Einsatzes wirtschaftlicher Macht zur Erzwingung politischen Wohlverhaltens war also selbst mitten in der Krise höchst zweifelhaft.

Aber wenn es für einen Appell an französische Ratio noch zu früh war, so nicht für die Mobilisierung der amerikanischen Regierung. Jene amerikanischen Politiker, von Präsident Herbert Hoover bis zu einflußreichen Senatoren und Kongreßabgeordneten, die sich, zusammen mit amerikanischen Finanziers und Geschäftsleuten, der britischen Auffassung angeschlossen hatten, der seltsame Kreislauf der zur Liquidierung des Weltkriegs als Regierungsschulden gezahlten Gelder - deutsche Reparationen an die ehemaligen Alliierten und deren Leistungen an ihren Gläubiger USA - sei nicht nur wirtschaftlich sinnlos, sondern wirtschaftlich außerordentlich schädlich, jene Amerikaner also fanden sich im Frühjahr 1931 zu einer allmählich fester werdenden Front zusammen. Dem stand freilich entgegen, daß eine eindeutige Mehrheit der Durchschnittsamerikaner - und mit ihr eine eindeutige Mehrheit der in den Medien laut werdenden öffentlichen Meinung - die Regierungsschulden nicht anders als private Schulden betrachtete und nach wie vor nicht den geringsten Grund sah, warum Briten und Franzosen die ihnen während des Krieges gewährten Kredite nicht zurückzahlen sollten; daß die Zahlungsfähigkeit der früheren Alliierten etwas mit den von Deutschland an diese zu zahlenden Reparationen zu tun hatte, war eine Einsicht, die der Majorität ebenfalls noch völlig fern $\mathrm{lag}^{72}$.

Die jähe und auch für die amerikanische Wirtschaft höchst bedenkliche Verschlimmerung der Krise in Deutschland, die nach dem 5. Juni eintrat, schuf nun jedoch eine Situation, die offensichtlich nach raschem Handeln verlangte. Und die Amerikaner, die in Deutschland investiert hatten, versäumten nicht, die Regierung an ihre Schutzpflicht zu erinnern. Wie sollte aber die Freiheit zum Handeln gewonnen werden? Daß die Vereinigten Staaten den ersten Schritt zu machen hatten, da niemand von Großbritannien und Frankreich ernstlich verlangen konnte, auf Reparationen zu ver-

70 Mackensen an AA, 19. 6. 1934; PA, R 74142.

71 Schlimpert an AA, 26. 8. 1931; PA, R 74142.

72 Noch im Frühjahr 1932 hatte sich daran nichts geändert, wie Sir Ronald Lindsay am 25. und 27. April aus Washington berichtete; DFBP, Second Series, Vol. III, Nr. 105, 107. 
zichten, wenn sie danach immer noch ihre Schulden an die USA verzinsen und amortisieren mußten, war ebenso klar wie die Schwierigkeit, die dem entgegenstand.

In dieser Zwickmühle - um so unangenehmer empfunden, als in der galoppierenden Krise jeder Tag kostbar schien - kam Präsident Hoover und seinen Mitarbeitern eine Idee, die einem taktischen Geniestreich gleichkam. Wie wäre es, so fragten sie sich, wenn der Präsident der Vereinigten Staaten allen beteiligten, betroffenen und interessierten Staaten den Vorschlag machte, Reparationen und alliierte Schulden für ein Jahr einfach auszusetzen? Der Einfall bestach durch drei Vorzüge, sämtlich geeignet, den Ausbruch aus einem ausweglos scheinenden Dilemma zu ermöglichen oder doch vorzubereiten. Zunächst einmal brachte er, sollte er verwirklicht werden, einen Aufschub der Zahlungen und damit eine Atempause, die angesichts der allgemeinen Finanzschwäche dringend gebraucht wurde. Außerdem: Ob nach Ablauf der Frist irgendwelche Zahlungen wieder aufgenommen werden konnten, war erfreulich zweifelhaft; jedenfalls ermöglichte das Feierjahr die Suche nach vernünftigen, praktikablen und dauerhaften Lösungen der bedrängenden Probleme. Zweitens stellte Hoovers Einfall, nach den nicht leicht zu interpretierenden und überdies auch widersprüchlichen Winken der vergangenen Monate, endlich ein deutlicheres Signal dar, daß die amerikanische Regierung den Zusammenhang zwischen Reparationen und alliierten Kriegsschulden nun sehe, verstehe und bei ihrer Europapolitik künftig berücksichtigen werde. Dies war ein formal noch unverbindliches, doch in Wahrheit kaum mehr rücknehmbares Versprechen an die Reparationsgläubiger, sie bei einer den internationalen Geldverkehr entlastenden Regelung der Reparationsfrage nicht auf ihren Schulden an die Vereinigten Staaten sitzenzulassen. Der dritte Vorzug bestand darin, daß Präsident Hoover seinen Vorschlag der eigenen Nation als einen Akt typisch amerikanischer Großmut präsentieren durfte, ohne jedoch den amerikanischen Steuerzahlern, wie es aussah, zuzumuten, den verdächtigen und listenreichen Europäern auch nur einen Dime zu schenken; nicht zum letzten Mal mußte eine amerikanische Regierung der Notwendigkeit genügen, einen richtigen oder für richtig gehaltenen Schritt auf internationalem Felde mit einem möglichst dramatischen Appell an jene eigentümliche Verbindung von generöser Hilfsbereitschaft und robustem Geschäftssinn zu fundieren, die während und nach der Abwendung von isolationistischer Selbstgenügsamkeit das außenpolitische Handeln einer Gesellschaft wie der amerikanischen prägte. Hoover versicherte sich der Rückendeckung durch wichtige Meinungsführer in Senat und Repräsentantenhaus, und Außenminister Stimson machte Mitte Juni den Versuch, sich mit dem britischen Premierminister telefonisch abzustimmen; das ist zwar aus technischen Gründen nicht ganz gelungen, doch der in London weilende Finanzminister Andrew W. Mellon, die Londoner Botschaft der USA und das Foreign Office 
besserten die Panne sofort aus ${ }^{73}$. Um den Weckruf an die Großherzigkeit der Amerikaner noch zu verstärken, erbat sich Hoover ein Telegramm des deutschen Reichspräsidenten, das einen Notschrei des deutschen Volkes an das amerikanische enthalten sollte, welchem Ersuchen Hindenburg prompt nachkam ${ }^{74}$; der greise Feldmarschall genoß in den Vereinigten Staaten großes Ansehen. Dann, am 20. Juni 1931, legte der Präsident seinen Vorschlag auf den Tisch der internationalen Staatengesellschaft.

Im Geschäft der Politik äußern sich die Akteure selten eindeutig, und so kommen alle Teilnehmer am Spiel auch nur selten zu einer sicheren Einschätzung der Motive und Ziele von Kontrahenten und Partnern; selbst bei dem Anschein nach eindeutigen Äußerungen wird fast immer, geradezu zwanghaft, die Frage gestellt, was denn wohl tatsächlich gemeint sei, was dahinterstecke. Auch Präsident Hoovers einfache und klare Anregung stieß auf das gewohnheitsmäßige Mißtrauen der europäischen Kabinette. Obwohl der Gedanke eines Feierjahres in der Luft gelegen hatte und - von amerikanischen Signalen angeregt - in den europäischen Hauptstädten, auch in Paris, seit Wochen gelegentlich erörtert worden war, wirkte Hoovers Aktion, als sie endlich kam, überraschend, ja sensationell, und alle Welt begann sogleich zu rätseln, welche Absichten die Amerikaner wirklich verfolgten und wie gefährlich die zu vermutenden Absichten für die eigenen Interessen sein könnten. Am wenigsten traf das auf die britische Regierung $\mathrm{zu}$, die von Washington klare Vorwarnungen - wenn auch sehr kurzfristig erhalten hatte und am Ende beim Ausbau der Hooverschen Idee zu einem formellen Vorschlag zu Rate gezogen worden war. Auch deckte sich der amerikanische Gedankengang so weitgehend mit den britischen Wünschen und Vorstellungen, daß er in London am raschesten und am besten verstanden wurde. Die hier beginnende und schnell intensivierte britisch-amerikanische Kooperation bei der politischen Behandlung der Reparations- und Schuldenfrage war eine der ersten Stationen in der Entwicklung eines „besonderen Verhältnisses" zwischen Großbritannien und den Vereinigten Staaten; mit Ausnahme einer kurzen Phase in der zweiten Hälfte der dreißiger Jahre, als Premierminister Neville Chamberlain sein Appeasement Hitlers ohne amerikanische Ein- und Widerrede betreiben wollte, sollte es für die Auseinandersetzung der westlichen Welt erst mit der nationalsozialistischen und dann mit der sowjetischen Gefahr größte Bedeutung erlangen.

Mehr aus Mangel an Interesse als auf Grund verständnisvoller und zutreffender Interpretation reagierte auch Italien gelassen; schließlich war Italiens Anteil an den Reparationen so bescheiden, daß ihr temporärer oder endgültiger, partieller oder vollständiger Wegfall keine stärkeren Gemütsbewegungen in Rom auslöste. Mussolini machte lediglich den Versuch, dem amerika-

74 AdRK, Die Kabinette Brüning, Bd. 2, Nr. 241. 
nischen Angebot eine Bedingung anzuhängen: Deutschland müsse, um in den Genuß des Feierjahres zu kommen, erst der deutsch-österreichischen Zollunion abschwören. Als das ruchbar - wenn auch noch nicht offiziell verlangt - wurde, erhielt aber der Duce aus Washington eine sehr streng gehaltene Mahnung, die hochherzige amerikanische Aktion dürfe keineswegs mit irgendwelchen europäischen Querelen vermengt werden ${ }^{75}$. Er zog sofort zurück und folgte wieder, wie ja in der Auseinandersetzung um die Zollunion bislang schon, dem Vorbild der britischen Regierung, die den Vorschlag Hoovers ungesäumt und ohne jeden Vorbehalt annahm, wie Sir Ronald Lindsay, der britische Botschafter in Washington, am 22. Juni dem Weißen Haus und dem State Department übermittelte ${ }^{76}$.

In Berlin hingegen herrschte Unsicherheit. War Erleichterung und Freude oder im Grunde sogar eine gewisse Enttäuschung angebracht? An sich durfte der Vorschlag des amerikanischen Präsidenten als ein weiterer - und unerwartet rascher - Erfolg der „Hier lieg ich mit einer ansteckenden Krankheit auf dem Schmerzenslager, nun kuriert mich mal!“-Taktik gewertet werden. Auch mußten die 1,6 Milliarden Reichsmark, die ein Feierjahr in der Kasse des Reiches belassen würde, als ein unverhofftes Geschenk zur Linderung der Nöte des Augenblicks eigentlich mit Dankbarkeit aufgenommen werden. Aber das war der Standpunkt des Finanzministers und des Präsidenten der Reichsbank, die im übrigen in jenen Sommermonaten durch die Bankenkrise in Schwierigkeiten gerieten, zu deren Überwindung auch das Präsent Herbert Hoovers nicht annähernd ausreichte. Die Leiter der Außenpolitik, Brüning und noch Curtius, glaubten in anderen Kategorien denken zu müssen. Beide waren, obwohl die Botschaft in Washington Indizien gemeldet hatte ${ }^{77}$, von der Initiative Präsident Hoovers völlig überrascht worden. Noch einen Tag vor dem 20. Juni hatte Außenminister Curtius in einer Chefbesprechung gesagt, „von den Amerikanern könne man ja zur Zeit gar nichts erwarten“78. Als nun das Angebot des Präsidenten vor ihnen lag - an dem Reichskanzler und Reichspräsident als nicht ganz freiwillige Bittsteller sogar noch hatten mitwirken müssen -, war wohl an Ablehnung nicht zu denken; im Gespräch mit dem amerikanischen Botschafter Frederic M. Sackett und durch die bereitwillige deutsche Beteiligung brachte Brüning die Zustimmung des Reiches ohne Zögern zum Ausdruck $^{79}$.

Andererseits tauchten aber doch Fragen auf. Kam das Moratorium nicht zu früh und war seine Laufzeit nicht zu kurz? $\mathrm{Zu}$ früh, weil das Elend

75 Aufzeichnung Bülow nach Gespräch mit dem italienischen Botschafter in Berlin, 25. 6. 1931; PA, R 29450.

76 Henderson an Lindsay, 22. 6. 1931; DBFP, Second Series, Vol. II, Nr. 69.

77 AdRK, Die Kabinette Brüning, Bd. 2, Nr. 341, Anm. 1.

78 AdRK, Die Kabinette Brüning, Bd. 2, Nr. 337.

79 AdRK, Die Kabinettc Brüning, Bd. 2, Nr. 350. 
Deutschlands noch nicht groß genug schien, um einen Generalangriff auf den Young-Plan zu begründen, zu eng begrenzt, weil nach nur einem Feierjahr die Forderung nach Wiederaufnahme der Zahlungen noch natürlich erscheinen und schwer abzuweisen sein mochte. Eben deshalb hatte die deutsche Reparationspolitik ja auf ein Moratorium von mindestens drei Jahren gezielt. Jedenfalls stand offenbar fest, daß Hoovers Schritt die Ankündigung eines Transferaufschubs fürs erste unmöglich machte. Wie sollte es weitergehen? Der Reichskanzler hatte dem amerikanischen Botschafter zwar gesagt, die Annahme des Vorschlags Hoovers bedeute nicht, daß Deutschland auf seine im Young-Plan verankerten Rechte verzichte ${ }^{80}$. Aber was besagte das jetzt? Wann und wie konnten die Mechanismen des Young-Plans gegen den Plan gewendet werden, solange Deutschland gar nicht zu zahlen brauchte oder nachdem es ein Jahr lang nicht gezahlt hatte? Angesichts der reparationspolitischen Grundtendenz Brünings war es in der Tat ungewiß, ob die amerikanische Aktion Deutschlands Reparationspolitik voran- oder durcheinanderbrachte.

In Frankreich schwankten Regierung und Öffentlichkeit zwischen Entsetzen und Empörung. Dabei ging es den Franzosen keineswegs mehr um Geld. Am 19. Juni hatte Botschafter v. Hoesch in Berlin dem Kanzler und einigen Kabinettsmitgliedern dargelegt, daß die französische Regierung inzwischen genaue Kenntnis davon habe, wie schlimm die Dinge in Deutschland stünden, und daß daher ihr Verständnis für etwaige deutsche Wünsche nach Entlastung groß sei; man rechne in Paris allgemein mit der Inanspruchnahme des nach dem Young-Plan zulässigen Transferaufschubs ${ }^{81}$. Jedoch, so fügte der Botschafter hinzu, könne er sich nicht vorstellen, daß "der Gedanke einer Revision des Young-Plans ernstlich Erfolg haben" werde ${ }^{82}$. Genau hier lag der Hase im Pfeffer. Nicht weniger klar als ihre britischen Kollegen erkannten die Franzosen, daß Hoovers Vorschlag eine Wende der amerikanischen Haltung in der Frage der alliierten Kriegsschulden ankündigte oder bereits den ersten Schritt dazu darstellte. Nun hatten aber die Zahlungen an die USA stets eine Begründung des französischen Reparationsanspruchs an Deutschland geliefert, keine moralische und keine juristische, jedoch eine finanziell einleuchtende, und mit der wachsenden Entfernung vom Kriege wurde die finanziell einleuchtende Begründung allmählich wichtiger als die moralische. Das hätte für normale Zeiten gegolten und galt naturgemäß erst recht in einer Periode globaler wirtschaftlicher Katastrophen. Wenn sich also abzeichnete, daß die USA bei einem vollständigen oder doch nahezu vollständigen Verzicht der Europäer auf deutsche Reparationen mit dem Verzicht auf die Eintreibung alliierter Kriegsschul-

\footnotetext{
80 AdRK, Die Kabinette Brüning, Bd. 2, Nr. 350, 351, 356.

81 AdRK, Die Kabinette Brüning, Bd. 2, Nr. 337.

82 Ebenda.
} 
den nachziehen würden, drohte, im Jahr 1931 und in der Wirtschaftskrise des Jahres 1931, die 1929/30 vereinbarte Reparationsregelung vollends unvertretbar zu werden. Fiel aber der Young-Plan, so öffnete sich die Flanke für den deutschen Sturm auf die übrigen Bollwerke des Versailler Vertrags; die Anzeichen waren ja in der Tat zahlreich und deutlich genug, daß das Deutsche Reich dann ungesäumt das Problem der militärischen Gleichberechtigung aufgreifen und die Umzeichnung der europäischen Landkarte versuchen werde. In Paris erschien mithin der Vorschlag des amerikanischen Präsidenten als eine tödliche Gefahr nicht nur für den Young-Plan, sondern für die Nachkriegsordnung Europas insgesamt. Das Entsetzen, das sich bei diesen Ausblicken einstellte, war deshalb von flammender Empörung begleitet, weil den Amerikanern unterstellt wurde, solchen Schaden aus reiner Selbstsucht anrichten zu wollen: Präsident Hoover, so hieß es schlichtweg, sei allein von der Absicht geleitet, den amerikanischen Investoren in Deutschland ihr Geld zu retten ${ }^{83}$.

So nahm die französische Regierung das Angebot des amerikanischen Präsidenten zwar grundsätzlich an, verband die Annahme aber mit derart einschneidenden Bedingungen, daß praktisch Ablehnung daraus wurde falls die französischen Wünsche unberücksichtigt bleiben sollten. Damit erzwang Paris eine Verhandlungsschlacht, die bis zum 6. Juli währte und wenn schon nicht die reale - finanzielle -, so doch die für die Weltwirtschaft nicht weniger wichtige psychologische Wirkung der Aktion Washingtons fast völlig ruinierte. Es ging um die Abwehr der dem Young-Plan drohenden Gefahr. Als Gegenmanöver hatte sich die französische Regierung ausgedacht, Großbritannien und den USA Regelungen für das Feierjahr abzuringen und Deutschland zu oktroyieren, die politisch unmißverständlich besagten und rechtlich ebenso klar kodifizierten, daß der Young-Plan im Prinzip in Kraft bleibe und nach Ablauf des Jahres auch wieder angewendet werde. Zunächst stellte die französische Regierung ein Maximalprogramm auf, das, von unbedeutenden finanzpolitischen Details abgesehen, als Kernstück drei Forderungen enthielt: Erstens solle Deutschland die sogenannten ungeschützten Annuitäten auch während des Feierjahres zahlen müssen; zweitens sei ein irgendwie beschaffenes Aufsichtsorgan einzusetzen, das zu kontrollieren habe, daß Deutschland die im Feierjahr eingesparte geschützte Annuität nur für wirtschaftliche - und nicht etwa für militärische - Zwecke ausgab; drittens gelte es Deutschland die Verpflichtung aufzuerlegen, die jetzt aufgeschobenen Zahlungen ab einem noch $\mathrm{zu}$ bestimmenden Zeitpunkt und innerhalb einer noch festzusetzenden Frist - zusätzlich zu den dann wieder normal laufenden Annuitäten - zu verzinsen und zu amortisie-

${ }^{83}$ Hoesch an AA, 24. 6. 1931; ADAP, Serie B, Bd. XVII, Nr. 202. 
ren $^{84}$. Konnte das durchgesetzt werden, war die Opferung der Sicherheit Frankreichs, zu der die dreist-egoistische Idee des amerikanischen Präsidenten unweigerlich führen mußte, noch einmal abgewendet.

Aber Frankreich focht bereits auf verlorenem Posten. Da war die inzwischen alle gekannten Dimensionen sprengende Krise der Weltwirtschaft und insbesondere der Wirtschaft Deutschlands; da war die britische Entschlossenheit, die eigene Politik an den Notwendigkeiten der Krisenbekämpfung und folglich am Appeasement des Deutschen Reiches zu orientieren; und da waren die Vereinigten Staaten, die sich bei ihrer seit 1919 ersten offiziellen politischen Intervention in europäischen Angelegenheiten einer der bedeutungsvollsten Aspekte des Hoover-Moratoriums - mit Vorsicht, jedoch zielbewußt parallel zum britischen Kurs bewegten. Mit einer solchen Konstellation konfrontiert, konnten die französischen Politiker, die in Paris zwei Wochen lang mit dem amerikanischen Finanzminister Mellon verhandelten, zwar noch hinhaltenden, aber nicht mehr erfolgreichen Widerstand leisten. Am Ende eines quälenden Feilschens, das der französischen Regierung mehrmals geharnischte Proteste der britischen Kollegen einbrachte ${ }^{85}$ und von den Amerikanern als Bestätigung ihres Vorurteils über die Unvernunft und kriminelle Kleinlichkeit kontinentaleuropäischer Politik aufgenommen wurde, stand nicht etwa, wie manche Franzosen meinten, ein halbwegs zufriedenstellender Kompromiß, sondern ein für die französischen Absichten nicht nur bedeutungsloser, sondern sogar überaus bedenklicher Scheinsieg. Wohl erreichten es die französischen Unterhändler, daß Deutschland angehalten wurde, die ungeschützte Annuität auch während des Feierjahres zu zahlen, jedoch ging das Geld nicht an Reparationsgläubiger, vielmehr an die Bank für Internationalen Zahlungsausgleich (BIZ), die dann Garantiebonds in entsprechender Höhe der Reichsbahn zur Verfügung stellte; das Deutsche Reich zahlte also de facto nichts mehr. Wenn sich Ministerpräsident Laval und seine Mitarbeiter schmeichelten, damit wenigstens die prinzipielle Weitergeltung des Young-Plans gerettet zu haben, so übersahen sie, daß sie dies mit der Anerkennung der These erkauft hatten, Deutschland könne in der Tat keine Reparationen zahlen, und daß sich angesichts der nun ganz deutlich gewordenen anglo-amerikanischen Auffassungen das Wörtchen „keine“ höchstwahrscheinlich alsbald in „nicht länger" verwandeln werde. Kam es dazu, so wurde auch die gleichfalls durchgesetzte Verzinsung und Amortisation der aufgeschobenen Zahlungen hinfällig. Was schließlich die Kontrolle der deutschen Finanzen anging, so hatten Großbritannien und die USA die französische Regierung auf die einseitige und bedeutungslose Erklärung zurückgedrängt, sie behalte sich

84 Lord Tyrrell an Henderson, 24. 6. 1931, 2. 7. 1931, 3. 7. 1931; DBFP, Second Series, Vol. II, Nr. 81, 114, 121. - Schulthess', 1931, S. $496 \mathrm{ff}$.

85 Henderson an Lord Tyrrell, 23. 6. 1931, 3. 7. 1931, 5. 7. 1931; DBFP, Second Series, Vol. II, Nr. 76, 123, 135. 
vor, von der Reichsregierung die erforderlichen Versicherungen zu erlangen $^{86}$.

Die Pariser Verhandlungen zwischen der französischen Regierung und Finanzminister Mellon fanden bezeichnenderweise ohne deutsche Beteiligung statt; Botschafter v. Hoesch war zwar in den Gang der Dinge eingeweiht, spielte aber lediglich die Rolle eines - Berlin freilich laufend informierenden - Beobachters, der den Verhandlungspartnern ab und an die Meinung der Reichsregierung zu einzelnen Streitpunkten übermittelte. Das entsprach eigentlich genau der Brüningschen Passivitäts-Taktik. Gleichwohl hatten Brüning und seine Minister keine Klarheit über das Ausmaß des deutschen Erfolgs oder, besser gesagt, der französischen Niederlage, wobei sie allerdings nicht wissen konnten, daß die britische Regierung selbst die Verpflichtung Deutschlands zu einer fiktiven Zahlung im Grunde als Verstoß wider den Geist des Hoover-Moratoriums mißbilligte ${ }^{87}$, und damit bereits auch als Erschwerung der schon erwogenen, wenn auch noch nicht ausgesprochenen Absicht betrachtete, während des Feierjahres zu einer auf Liquidierung hinauslaufenden endgültigen Regelung der Reparationsfrage zu gelangen; solche Kenntnis wäre gewiß tröstlich gewesen. So aber überschätzte man in Berlin die Resultate des zähen französischen Verhandelns, und in einer Hinsicht glaubte man sogar Grund zur Unzufriedenheit zu haben. Anders als vor dem 20. Juni sah sich die Reichsregierung nämlich unvermutet anglo-amerikanischem Druck ausgesetzt, den Franzosen politisch entgegenzukommen. Plötzlich wurden nicht nur der britische Außenminister und die Berliner Vertreter des Foreign Office, sondern im Namen Präsident Hoovers auch Botschafter Sackett bei Brüning, Curtius und Bülow mit der Aufforderung vorstellig, die hochherzige Handlung der Vereinigten Staaten vor allem mit zwei deutschen Konzessionen zu honorieren: mit dem Verzicht, worauf namentlich die Briten Wert legten, auf die deutsch-österreichische Zollunion und mit dem Verzicht auf den Bau des Panzerkreuzers B, was insbesondere die Amerikaner haben wollten ${ }^{88}$. Solange die Pariser Verhandlungen zwischen Schatzsekretär Mellon und der französischen Regierung im Gange waren, ließen London und Washington jedoch wissen, daß keine demütigende öffentliche Erklärung erwartet werde, vielmehr eine interne Zusicherung der Reichsregierung genüge ${ }^{89}$.

Die Leiter der britischen und der amerikanischen Außenpolitik verfolgten dabei drei Zwecke. Erstens hofften sie mit solchen - als Mittel zur par-

86 Lord Tyrrell an Henderson, 7. 7. 1931; DBFP, Second Series, Vol. II, Nr. 148.

87 Simon an Tyrrell, 18. 1. 1932; DBFP, Second Series, Vol. III, Nr. 37.

88 Aufzeichnungen Bülow über Unterredungen Brüning - Sackett, 30.6. 1931, 1. 7. 1931; AdRK, Die Kabinette Brüning, Bd. 2, Nr. 350, 351. - Henderson an Newton, 29. 6. 1931, Henderson an Lindsay, 29.6. 1931, Lindsay an Henderson, 1.7. 1931, Henderson an Newton, 2. 7. 1931; DBFP, Second Series, Vol. II, Nr. 93, 94, 109, 113.

89 Aufzeichnung Bülow über Unterredung Brüning - Sackett, 2. 7.1931; AdRK, Die Kabinette Brüning, Bd. 2, Nr. 356. 
tiellen Befriedigung des Sicherheitsbedürfnisses Frankreichs geeigneten deutschen Gesten die Bockbeinigkeit der französischen Unterhändler überwinden und die Pariser Regierung zu einer Politik der wirtschaftlichen Vernunft bewegen zu können. Diese Absicht führte sie alsbald dazu, von Berlin auch noch - was jedenfalls die Haltung der Regierung angehe - eine mehrjährige Suspendierung der territorialen Ansprüche Deutschlands an Polen zu verlangen. Zweitens dachte man in London und Washington mehr und mehr schon an die kommende Abrüstungskonferenz. Um deren Start ein günstiges Klima zu verschaffen und wiederum um Frankreich zu beeindrucken, dessen Abrüstungsbereitschaft offensichtlich dringend der Stimulierung bedurfte, hielten Engländer und Amerikaner, die der Konferenz Erfolg wünschten und an den Erfolg auch noch glaubten, deutsche Zugeständnisse für unumgänglich. Drittens mußten die Regierungen in London und Washington eine Mehrheit in den eigenen Ländern davon überzeugen, daß das finanzielle Appeasement Deutschlands gerechtfertigt, richtig und notwendig sei. Eine derartige Überzeugungsarbeit fiel schwerer, wenn die in Großbritannien und erst recht in den USA vorhandene Opposition mit dem Finger darauf deuten konnte, daß das angeblich in verzweifelter finanzieller Lage befindliche und daher mit großen finanziellen Opfern der Westmächte zu rettende Deutsche Reich doch genügend Geld habe, um Großkampfschiffe zu bauen; und der Panzerkreuzer B wie der geplante Panzerkreuzer $\mathrm{C}$ waren in der Tat keine kleinen Minenräumboote und keine Zerstörer, sondern - trotz der gemäß den Versailler Bestimmungen relativ bescheidenen Tonnage - sowohl für den Kaperkrieg wie für die Teilnahme an Seegefechten ingeniös konstruierte Großkampfschiffe. Letzterer Gesichtspunkt ist der Reichsregierung vor allem vor Augen gehalten worden ${ }^{90}$, aber auch die beiden anderen Zwecke, die hinter dem anglo-amerikanischen Appell an die deutsche Konzessionsbereitschaft standen, sind Brüning und dem Auswärtigen Amt wieder und wieder erläutert worden: erst in einem Ton, dessen ruhige Höflichkeit der Erwartung selbstverständlicher Folgsamkeit entsprang, und dann in Tönen wachsender Erregung, Gereiztheit und schließlich ungläubiger Verärgerung ${ }^{91}$.

Die Reichsregierung gab sich nämlich mißverstanden, zu Unrecht beargwöhnt, grundlos belästigt und zeigte sich in der Sache gänzlich unzugänglich. Dabei erboste die britischen und amerikanischen Politiker und Diplomaten vor allem die Klage ihrer deutschen Kollegen, daß immer nur von

90 So Henderson zu Neurath, 30. 6. 1931; DBFP, Second Series, Vol. II, Nr. 105. Zur Erhöhung der Forderungen Bülow an Missionen in Washington, Paris, London, Rom, 11. 7. 1931; PA, R 28229.

91 Der britische Geschäftsträger in Berlin, Basil Newton, betonte am 3. 7. 1931 in cinem Gespräch mit Außenminister Curtius, „welch beklagenswerter Eindruck entstehen müsse, wenn Deutschland, während andere Länder jeden Nerv anspannten, um zu helfen, sich einfach zurücklehne und jeden eigenen Beitrag verweigere“; DBFP, Second Series, Vol. II, Nr. 120. 
Deutschland politische Konzessionen verlangt würden und daß solch ungerechte Einseitigkeit nicht länger hingenommen werden könne: als sei der, wie es im Augenblick aussah, mindestens einjährige Verzicht der ehemaligen Kriegsgegner auf deutsche Reparationen weder eine Konzession noch überhaupt erwähnenswert. Am 1. Juli sagte Botschafter Sackett in einem Gespräch mit Brüning unumwunden, wie Bülow notierte, in Washington sei „der Eindruck entstanden ..., daß wir untätig dabei säßen, während die übrige Welt ungeheure Anstrengungen mache, um uns zu Hilfe zu kommen"92. Als die amerikanisch-französischen Verhandlungen in Paris - kurz vor ihrem erfolgreichen Abschluß - in eine tiefe Krise zu geraten schienen, verstärkten London und Washington den Druck auf Berlin und forderten jetzt auch, zur kräftigeren Beeinflussung der Pariser Atmosphäre, eine öffentliche Bekundung des deutschen - politischen - guten Willens. Am 2. Juli suchte Sackett den Reichskanzler erneut auf und legte ihm dringend nahe, wenigstens eine Erklärung abzugeben, daß während des Hoover-Jahres das Heeresbudget jedenfalls nicht erhöht werde. Es sei „die Sorge der Amerikaner und auch weiter anderer Kreise ..., daß Deutschland die Gelder, die unter großen Opfern ihm durch den Schuldennachlaß zur Verfügung gestellt würden, für Rüstungszwecke verwende“. Daher der Wunsch nach einer entsprechenden Verlautbarung der Reichsregierung, in der außerdem festgehalten werden sollte, daß der Panzerkreuzer B während des Hoover-Feierjahres nicht gebaut werde ${ }^{93}$.

Der Weltöffentlichkeit und damit der deutschen Öffentlichkeit mitzuteilen, daß der Panzerkreuzer B 1931/32 nicht gebaut werde, lehnte Brüning jedoch rundweg ab. Dabei kam es ihm weniger darauf an, die deutsche Öffentlichkeit nicht gegen sich aufzubringen, vielmehr nahm er Rücksicht auf die Gefühle und Ziele der Stützen seiner Macht: Reichspräsident und Reichswehr. Zwar deckten sich seine eigenen Empfindungen und Absichten durchaus mit denen seiner Auftraggeber, doch durfte er sich als Mandatar mittlerweile nicht einmal mehr taktisch bedingte Abweichungen gestatten. Strikte Rücksichtnahme war zu schierer Notwendigkeit geworden, und hier ist ein Lebensgesetz der Regierung und des Systems Brüning zu erkennen: Je mehr sich der internationale Spielraum Deutschlands erweiterte, desto enger wurde die außenpolitische Handlungsfreiheit des Kabinetts durch die innenpolitische Konstellation eingeschnürt. Brüning verstand sich lediglich zu einer nicht-öffentlichen Versicherung, „daß im nächsten Jahr nicht, wie beabsichtigt, der Panzerkreuzer C auf Kiel gelegt bzw. Gelder für den Bau dieses Schiffes in den Etat eingestellt würden“, und zu einer zusätzlichen Erklärung, daß die finanziellen Erleichterungen, dic das Hoover-Moratorium bringe, nicht zu einer Erhöhung der militärischen Ausgaben des Rei- 
ches genutzt würden. Auch letztere Äußerung wollte der Kanzler nur intern abgeben ${ }^{94}$. Als aber Sackett noch einmal erschien, am 5. Juli, und Brüning auseinandersetzte, daß Präsident Hoover die drei Tage zuvor erbetene - und im Auswärtigen Amt auch formulierte - Erklärung veröffentlicht brauche, um die Pariser Verhandlungen vor dem Scheitern zu retten, willigte der Reichskanzler in die Publizierung durch die amerikanische Regierung ein, freilich ohne, obwohl das von Sackett abermals verlangt worden war, ein einziges Wort über die Schiffsbauten zu dulden, und nicht ohne unwilliges, ja vorwurfsvolles Gebrumm: Präsident Hoover übernehme eine „schwere Verantwortung“, sagte Brüning, da die Veröffentlichung der deutschen Erklärung nur französischen Appetit auf weitere politische Konzessionen Deutschlands wecken werde ${ }^{95}$.

Auch was die Zollunion anging, wiesen der Kanzler, der Außenminister und Staatssekretär v. Bülow jede angelsächsische Mahnung, die Sache im Interesse der Beschwichtigung Frankreichs doch endlich fallenzulassen, zu diesem Zeitpunkt noch schroff zurück ${ }^{96}$; allerdings war in Berlin noch unbekannt, daß die Österreicher ihre Desertion aus dem Projekt der britischen Regierung bereits am 17. Juni angekündigt hatten ${ }^{97}$. Erst am 16. Juli, nachdem die österreichische Desertion auch in Berlin zur Kenntnis genommen worden war und die Preisgabe der ohnehin obsoleten Zollunion jeglichen Konzessionscharakter verloren hatte, versprach Brüning dem britischen Botschafter in Berlin, eine Lösung des Problems zu finden, die sowohl die Regierung Seiner Majestät wie die französische Regierung zufriedenstellen werde ${ }^{98}$.

Die Dickfelligkeit, mit der das Kabinett Brüning alle in Deutschland als Ansinnen charakterisierten Aufforderungen ignorierte oder unwillig ablehnte, ein Geschenk von 1,6 Milliarden Reichsmark mit ein paar freundlichen politischen Gesten zu quittieren, zeigte sich besonders aufreizend am 13. Juli. Kaum war am 6. Juli die amerikanisch-französische Einigung erreicht und anschließend das Hoover-Moratorium offiziell in Kraft gesetzt worden, überreichte der Botschafter in London, Baron Neurath, ein Memorandum, in dem die Reichsregierung auf den erfreulichen Gang der Dinge, der nicht zuletzt beharrlicher angelsächsischer Einwirkung auf Paris zu danken war, nur mit Klagen, der schroffen Demonstration politischer Intransigenz und der erneuten Anmeldung des ohne ausländische Hilfe sozusagen stündlich zu erwartenden Zusammenbruchs der deutschen Wirtschaft antwortete. An die Klage, die französischer Unvernunft zu dankende lange Verhandlungsrunde in Paris habe die Wirkung des Hoover-Moratoriums

\footnotetext{
94 Ebenda.

95 AdRK, Die Kabinette Brüning, Bd. 2, Nr. 362.

96 Z. B. Aufzeichnung Curtius über Unterredung mit Newton, 3. 7. 1931; PA, R 28000.

97 Phipps an Henderson, 17. 6. 1931; DBFP, Second Series, Vol. II, Nr. 59.

98 Rumbold an Vansittart, 16. 7. 1931; DBFP, Second Series, Vol. II, Nr. 210.
} 
fast vernichtet, schloß sich der Vorwurf, Frankreich nutze die deutschen Nöte, um politische Konzessionen Deutschlands zu erpressen (zum Beispiel Panzerkreuzer B und Zollunion), und obwohl die deutsche Regierung solche Konzessionen aus innenpolitischen Gründen doch nicht machen könne, finde Frankreich bei seinen Erpressungsversuchen sogar die Unterstützung Großbritanniens. Der Hinweis, die Erörterung politischer Forderungen sei in ruhigerer Atmosphäre und in größerem Rahmen durchaus möglich, vermochte die Verweigerung deutscher Konzessionen nicht abzumildern, da sofort der Zusatz folgte, auch dann müßten die Westmächte aufhören, von Deutschland einseitige Zugeständnisse zu verlangen. Danach kam die Mitteilung, falls nicht sofort Hilfe geleistet werde, und zwar durch die Gewährung von Krediten, seien in Deutschland Zusammenbrüche unvermeidlich, die wiederum katastrophale Resultate für ganz Mitteleuropa haben würden 99 .

In jeder deutschen Klage und in jedem deutschen Vorwurf steckte ein Kern Wahrheit. Es war nicht zu bestreiten, daß Frankreichs hartnäckige Verteidigung des Young-Plans die psychologische Wirkung der amerikanischen Aktion erheblich reduziert hatte. Es war ebenfalls nicht zu leugnen, daß Großbritannien und partiell auch die Vereinigten Staaten sich Mühe gegeben hatten, Deutschland zu politischen Konzessionen anzuhalten. Und die wirtschaftliche Lage hatte sich durch die Bankenkrise tatsächlich erneut dramatisch verschlechtert. Aber ein klares Wort aus Berlin, die Reichsregierung denke nicht daran, auf die Liquidierung des Young-Plans hinzuarbeiten, hätte die französisch-amerikanischen Debatten sofort beendet, und die anglo-amerikanischen Wünsche waren in der gegebenen Situation keineswegs unbillig. Davon abgesehen, mußte es als ein Zeichen schnöden Undanks erscheinen, daß es die Reichsregierung für richtig hielt, die in der Reparationsfrage unbestreitbare amerikanisch-britische Bundesgenossenschaft gegen Frankreich mit Stillschweigen zu übergehen und überdies an jene Stelle, an die einige angemessene Worte der Anerkennung gehört hätten, etliche bittere Vorwürfe zu setzen. Vor allem eines aber weckte in London Empörung: Die Reichsregierung ließ in ihrem Schreiben jedes Gefühl dafür vermissen, daß die Krise, die es zu bekämpfen galt, gesamteuropäische, ja weltweite Dimensionen angenommen hatte. Nach dem politischen Fauxpas, den sie sich leistete, brachte sie zwar die Rede auf Schwierigkeiten außerhalb Deutschlands, jedoch nur zur Unterstreichung der eigenen Hilfsbedürftigkeit, als Glied einer fast schon erpresserischen Argumentation: Helft uns, sonst geht es euch schlecht! Niemand in London oder Washington nahm es Brüning und seinen Kollegen übel, daß sie ihre Politik an deutschen Interessen orientierten und diese Interessen auch zäh verfochten. Das taten selbstverständlich alle und nicht selten auch mit jenem „Heiligen Egois-

99 Henderson an Rumbold, 13. 7. 1931; DBFP, Second Series, Vol. II, Nr. 185. 
mus“, den die Staatsräson für erlaubt erklärte oder doch als unvermeidlich rechtfertigte. Aber nur noch die eigenen Interessen zu sehen und jegliche Mitverantwortung für das Geschick anderer und für die Gesamtheit der internationalen Staatengesellschaft abzulehnen, jedenfalls dem Anschein nach, bescherte der Reichsregierung den nämlichen herben Tadel, den mit ihrem vergleichbaren Verhalten die französische Regierung auf sich zog. Daß das Kabinett Brüning eine erneute Bekräftigung politischer Intransigenz unmittelbar und ungeniert mit erneutem Flehen um Finanzhilfe verband, machte aus seinem Aide mémoire vom 13. Juli 1931 in der Tat eine wahrhaft bemerkenswerte Manifestation nationaler Egozentrik und ihrer Umsetzung in naiv-dreiste politische Taktik. Noch bemerkenswerter war indes, daß die Reichsregierung, wenn sie dermaßen die Wohlfahrt Europas und der Welt den Zielen deutscher Revisionspolitik unterordnete, völlig unbestraft blieb.

Das lag in erster Linie an der Haltung Großbritanniens. Wohl hatte gerade Außenminister Henderson von der deutschen Regierung verlangt, die ihr zuteil werdende Finanzhilfe mit politischen Gesten zu honorieren, welche sowohl in der Reparations- und Schuldenfrage wie im Hinblick auf die anstehende Abrüstungskonferenz zur Beruhigung Frankreichs und damit zur Pazifizierung des europäischen Kontinents beitragen konnten; auch die Briten gingen dabei von der Vorstellung aus, Europas wirtschaftliche Erholung setze eine Besserung des politischen Klimas voraus. So hatte er die Erklärung, die der Reichsregierung von Präsident Hoover abgehandelt worden war, als "gänzlich unangemessen“ hart gegeißelt: Daß Deutschland während des Feierjahres seine Militärausgaben nicht erhöhe, sei ja wohl so selbstverständlich, daß dies keiner besonderen Erklärung bedürfe. Was man von der deutschen Regierung mit Fug und Recht erwarten und fordern dürfe, sei das öffentliche Versprechen, im Feierjahr das Militärbudget zu reduzieren und namentlich kein zweites "Taschenschlachtschiff" - so wurden die Panzerkreuzer A, B und C genannt - zu bauen; auch gehöre es sich, daß Berlin den Westmächten zusage - ohne einen öffentlichen Verzicht auszusprechen -, die geplante deutsch-österreichische Zollunion nicht weiter verfolgen $\mathrm{zu}$ wollen 100 .

Nicht nur die deutsche Regierung bekam Hendersons Grimm zu spüren, sondern auch die amerikanische ${ }^{101}$, die ja nach einigem Hin und Her die deutsche Erklärung als ausreichend akzeptiert hatte. Er suchte Washington wieder auf seinen härteren Kurs zu ziehen, was naturgemäß nicht mehr gelingen konnte, doch machte er auch ohne amerikanische Schützenhilfe Ber-

100 Henderson an Lindsay, 7. 7. 1931; DBFP, Second Series, Vol. II, Nr. 153.

101 Ebenda. Am 4. 7. 1931 wies Henderson seinen Botschafter in Washington erneut an, die amerikanische Regierung zur Unterstützung der britischen Forderungen an Berlin aufzufordern: „Die jetzt gegebene Möglichkeit, die deutsche Regierung im Interesse der Wiederherstellung von Vertrauen zu dieser Geste zu bewegen, könnte nicht wiederkehren. "DBFP, Second Serie, Vol. II, Nr. 131. 
lin mehrmals klar, wobei er auf jede diplomatische Verbrämung verzichtete, daß Deutschlands Nachbarn und alle von der derzeitigen Krise betroffenen Staaten - zumal jene, die dem Reich finanziell zur Seite stünden - ein Recht auf eine deutsche Geste hätten, „die Europa von der Ernsthaftigkeit des Wunsches Deutschlands überzeugen würde, seinen Beitrag zum allgemeinen Befriedungswerk zu leisten"102. Wenn er in solchem Sinne mit Baron Neurath sprach, durfte er sogar den Eindruck gewinnen, daß der Botschafter im Grunde seine Meinung teilte ${ }^{103}$. Die Reichsregierung hingegen, dieser Schluß mußte gezogen werden, war zu keinem Entgegenkommen zu bewegen. Das verstärkte Hendersons Verstimmung. Nachdem ihm Neurath das Aide mémoire der Reichsregierung vom 13. Juli präsentiert hatte, noch am selben Tag, bemerkte er überaus kühl, er nehme die Ansichten der deutschen Regierung zur Kenntnis, wolle aber dem Botschafter nicht verhehlen, wie sehr er es bedauere, daß die Deutsche Regierung keine Möglichkeit gesehen habe, einige der von ihm schon vor mehreren Wochen angeregten Gesten zu machen, die bei der Schaffung einer besseren Atmosphäre in ganz Europa hilfreich sein würden ${ }^{104}$. Für einen britischen Minister war das in jener Zeit eine scharfe Sprache.

Aber welchen Schluß zog die Regierung Seiner Majestät aus alledem? Sie kam zu dem Ergebnis, daß es angebracht und sogar unvermeidlich sei, das Appeasement Deutschlands ohne Beachtung der deutschen Sünden fortzusetzen. Praktisch hieß das, jetzt, nach dem Beginn des Hooverschen Feierjahres, auf der Realisierung einer Absicht zu bestehen, die London noch während der Pariser Verhandlungen zwischen den USA und Frankreich gehegt und auch bereits geäußert hatte, nämlich der Absicht, ehebaldigst, wenn irgend möglich noch im Juli, eine Konferenz der am Reparationsproblem interessierten Staaten anzuberaumen, auf der beraten und beschlossen werden müsse, was denn nach Ablauf des Hoover-Moratoriums geschehen solle. Der Konferenzvorschlag alleine signalisierte schon deutlich genug, daß die britische Regierung keineswegs vorhatte, im Juli 1932 einfach zum Young-Plan zurückzukehren. Für eine solche Rückkehr hätte es keiner neuen Beschlüsse bedurft. Daß die britische Regierung als Konferenzort nicht Paris, sondern London wünschte, deutete in die gleiche Richtung ${ }^{105}$. Obwohl die parlamentarische Basis des Labour-Kabinetts MacDonald in jenen Wochen immer brüchiger wurde, was denn auch im August 1931 zum Sturz des Kabinetts und zur Bildung der aus abgespaltenen Labour-Politikern, Liberalen und Konservativen zusammengesetzten ersten „Nationalen

102 Henderson an Newton, 9. 7. 1931; DBFP, Second Series, Vol. II, Nr. 171.

103 Ebenda.

104 Henderson an Newton, 13. 7. 1931; DBFP, Second Series, Vol. II, Nr. 185.

105 Memorandum Henderson on Discussions in Paris, July 15 - July 19, for Meeting of a Conference in London to consider German Financial Situation, 1931; DBFP, Second Series, Vol. II, Nr. 193. 
Regierung " unter MacDonald führte, handelten der Premier und Außenminister Henderson energisch, ja sogar hemdsärmelig. Henderson hielt sich vom 15. bis zum 19. Juli in Paris auf, wo er - angespornt auch durch Washington - die französische Regierung erstens von der Notwendigkeit einer sofortigen Konferenz über die finanzielle Lage Deutschlands zu überzeugen suchte und zweitens dafür gewinnen wollte, die Konferenz in Londoner Atmosphäre zu veranstalten. Als er im ersten Punkt mehr scheinbare denn reale und im zweiten Punkt nicht einmal scheinbare Fortschritte machte, faßten Premier MacDonald und sein Kabinett kurzerhand den Entschluß, die interessierten Mächte eben ohne französische Zustimmung nach London einzuladen ${ }^{106}$.

Die Einladung erging am 16. Juli, lautete auf den 20. Juli und richtete sich an die USA, Frankreich, Belgien, Italien, Japan und natürlich Deutschland. Ein zuvor geplanter Besuch MacDonalds und Hendersons in Berlin wurde zugunsten der Konferenz zurückgestellt. Angesichts einer solchen Demonstration britischer Entschlossenheit, hinter der, wie sie wußten, auch die Vereinigten Staaten standen, wichen die Franzosen zurück. Sie akzeptierten die britische Grundthese, daß Deutschland unbedingt geholfen werden müsse, und erklärten sich bereit, am 20. Juli nach London zu gehen ${ }^{107}$. Allerdings machten sie ihre Teilnahme an der Londoner Konferenz von zwei Bedingungen abhängig: Reichskanzler Brüning und Außenminister Curtius müßten bei ihrer Reise nach Großbritannien einen Umweg über Paris und die in $\mathrm{Pa}$ ris zu führenden französisch-deutschen Gespräche müßten einen günstigen Verlauf nehmen. Briten und Amerikaner ließen sich diesen Versuch, den Anschein einer Pariser Deutschland-Konferenz zu retten, gefallen und bewogen auch die Reichsregierung dazu, London über Paris anzusteuern ${ }^{108}$.

Am 18. Juli trafen Brüning und Curtius in der französischen Hauptstadt ein, und damit begann dort der erste Akt eines der seltsamsten diplomatischen Schauspiele jener an solchen Stücken wahrlich nicht armen Jahre. Die französische Regierung trat plötzlich als aufrichtiger und zu großzügigster Hilfe bereiter Schutzengel Deutschlands auf. Nicht allein Außenminister Briand, der unentwegte Freund der deutsch-französischen Verständigung, agierte in dieser Rolle, sondern ebenso Ministerpräsident Laval und Finanzminister Flandin ${ }^{109}$; die Vertreter des rechten Flügels, so Kriegsminister André Maginot, zeigten freilich, daß sie mit den deutschen Politikern nicht zu-

106 Ebenda.

107 Ebenda.

108 Ebenda.

109 Notes of Conversation held at the Ministry for the Interior, Place Beauveau, Paris, on July 19, 1931, at 10 a.m.; DBFP, Second Series, Vol. II, Nr. 219. - Aufzeichnung Ministerialdirektor Lutz Graf Schwerin v. Krosigk über die Besprechung des Reichskanzlers mit der französischen Regierung in Paris, 18.Juli 1931, Bericht Brünings und Curtius' über die Verhandlungen in Paris und London, 25.7. 1931; AdRK, Die Kabinette Brüning, Bd. 2, Nr. 398, 408. 
sammentreffen wollten, indem sie demonstrativ Paris verließen ${ }^{110}$. Briand spielte seinen Part mit Herz, und auch Laval war nicht ohne Überzeugung bei der Sache; der Regierungschef begann angesichts der allenthalben ausgebrochenen wirtschaftlichen und politischen Krisen unter der Furcht vor der Sowjetisierung Europas zu leiden; als Bollwerk gegen diese Gefahr hielt er eine Vorstellung, die ihn nie mehr verlassen und über seine dominierende Mitwirkung in den Regierungen Vichy-Frankreichs am 16. Oktober 1945 vor ein französisches Erschießungspeloton führen sollte - ein gesundes und starkes Deutschland für notwendig 111 . Von derartigen individuellen Motiven abgesehen, wählte das französische Kabinett seinen Kurs aus drei Gründen: Erstens brach sich die Einsicht Bahn, daß gegenüber der britischen und amerikanischen Entschlossenheit reine Negation nicht aufrechtzuerhalten war. Zweitens hatte doch auch die Erkenntnis immer mehr Anhänger gewonnen, daß sich Paris um Europas und damit schließlich auch Frankreichs willen an der Sanierung Deutschlands beteiligen müsse. Drittens bemächtigte sich der Regierung die Vision, daß man aus der Not eine Tugend machen und Deutschlands jetzt noch gestiegene Hilfsbedürftigkeit ausnutzen könne, um das Reich doch noch am drohenden Ausbruch aus den Versailler Abhängigkeiten zu hindern und sogar fester denn je an den Status quo zu binden ${ }^{112}$.

So waren es die Franzosen, die, den im Frühjahr in der Empörung über das Zollunionsprojekt abgerissenen Faden wieder aufnehmend, bei Henderson und bei dem in Paris - wie dann in London - anwesenden amerikanischen Außenminister Stimson noch vor Erscheinen der Deutschen darauf drängten, Deutschland einen langfristigen Kredit in Höhe von etlichen Milliarden Reichsmark zu gewähren, allerdings gegen einige Bedingungen: Ein so hoher Kredit, sagten Laval und Flandin, erfordere eine gewisse internationale Kontrolle seiner Verwendung, namentlich sei dafür zu sorgen, daß Deutschland das Geld nicht für militärische Zwecke ausgebe oder an ostund südosteuropäische Länder weiter verleihe und damit zur Stärkung seiner politischen Position auf dem europäischen Kontinent nutze; Gestalt und Zusammensetzung des Aufsichtsorgans blieben offen. Auch habe Deutschland Verzinsung und Amortisation der Anleihe zu garantieren; wiederum blieb offen, wie Sicherheiten aussehen konnten. Vor allem aber sei vom Deutschen Reich ein "politisches Moratorium“ zuzugestehen, was heiße, daß sich die Reichsregierung verpflichten müsse, für eine noch festzulegende Periode - fünf, acht, zehn Jahre - auf den Bau militärischer Lu-

110 Botschaft Paris an AA, 24. 7. 1931; PA, R 70505.

111 Aufzeichnung Curtius über Unterredung mit Laval am 26. 7. 1931, 27. 7. 1931; AdRK, Kabinette Brüning, Bd. 2, Nr. 490. Curtius hat Lavals Äußerungen freilich nicht ganz ernst genommen.

112 Notes on Conversation between the Marquess of Reading and MM. Laval, Briand and Flandin, Paris, 7. 10. 1931; DBFP, Second Series, Vol. II, Nr. 266, 267. 
xusartikel wie die Panzerkreuzer B und C ebenso zu verzichten wie auf die propagandistische und praktische Verfechtung territorialer Revisionsansprüche; außerdem erwarte Frankreich von der deutschen Regierung die Zusage, während der Laufzeit der Anleihe energischer als bisher gegen chauvinistische Demonstrationen der radikalen Rechten in Deutschland zum Beispiel gegen Stahlhelmkundgebungen - Front zu machen, zumindest in Form deutlicher Distanzierung. Schließlich sei auch Klarheit darüber zu schaffen, daß Deutschland nach der Wiedererlangung seiner finanziellen Stabilität zu den Reparationszahlungen des Young-Plans zurückzukehren habe; die Anleihe und ihre erhoffte positive Wirkung dürften nicht auf eine Preisgabe des Plans hinauslaufen ${ }^{113}$.

Vom letzten Punkt abgesehen, klangen die von Laval und Flandin genannten Bedingungen für Henderson und Stimson so vertraut wie vernünftig. Daher kamen die Vertreter Frankreichs mit denen Großbritanniens und der USA fast mühelos zu einer Verständigung. Zwar wurden viele Einzelheiten, darunter wichtige, weder besprochen noch gar geklärt; das wäre ja auch dem Sinne dieses offiziell nicht als Konferenz geltenden Treffens zuwidergelaufen. Außerdem tauchten gelegentlich Streitpunkte auf, die man unerledigt ließ. So verlangten die Franzosen, daß der Kredit, der auf den $\mathrm{Ka}$ pitalmärkten zu mobilisieren sei, von den Regierungen garantiert werden müsse, womit die Briten keineswegs einverstanden waren ${ }^{114}$. Stimson wiederum stipulierte, daß der Bedienung der Anleihe durch Deutschland Priorität vor künftigen deutschen Reparationszahlungen einzuräumen sei, was Laval kategorisch verneinte ${ }^{115}$. Aber die Frage, ob Deutschland einen langfristigen Kredit brauche und erhalten solle, wurde nach einigen Gesprächsrunden so behandelt, als sei sie grundsätzlich bejahend entschieden. Der deutsche Kreditbedarf wurde auf rund 500 Millionen Dollar geschätzt, und die Gesprächspartner betrachteten es offensichtlich als vereinbart, daß ein beträchtlicher Teil dieser Summe von Frankreich aufzubringen sei, der verbleibende Teil von Großbritannien und den Vereinigten Staaten ${ }^{116 .}$

Diesen Stand der Dinge fanden Brüning und seine Delegation vor, als sie am 18. Juli nach Paris kamen. Daß es die Franzosen fertiggebracht hatten, einen der wichtigsten Punkte der Londoner Tagesordnung doch bereits auf den Pariser Tisch zu legen und von einem französisch-britisch-amerikanischen Kreis auch erörtern, ja, wie es aussah, schon entscheiden zu lassen, paßte eigentlich gar nicht in Brünings Konzept. Der Reichskanzler war mit

113 Memorandum Henderson on Discussions in Paris, Lord Tyrrell an Vansittart, 15. 7. 1931, Lord Tyrrell an Vansittart, 16. 7. 1931, Notes of a Conversation held at the Ministry for the Interior; DBFP, Second Series, Vol. II, Nr. 193, 194, 199, 219. - Aufzeichnung Curtius über Besprechung mit französischen Ministern, 18. 7. 1931, Bülow an Hoesch, 18. 7. 1931; PA, $\mathrm{R} 28255 \mathrm{k}$.

114 Vansittart an Lord Tyrrell, 16. 7. 1931; DBFP, Second Series, Vol. II, Nr. 208.

115 Lord Tyrrell an Vansittart, 16. 7. 1931; DBFP, Second Series, Vol. II, Nr. 199.

116 Memorandum Henderson on Discussions in Paris; DBFP, Second Series, Vol. II, Nr. 193. 
der Absicht in die französische Hauptstadt gekommen, sich hier ebenso zu verhalten wie bei seinem Besuch in Chequers ${ }^{117}$, das heißt, er wollte weiter nichts, als die deutschen Zustände in den düstersten Farben malen und damit - wenn er denn um die Reise nach Paris schon nicht herumkam - für künftige reparationspolitische Schritte der Reichsregierung vielleicht auch den harten französischen Boden etwas auflockern. Auf ernsthaftere Verhandlungen gedachte er sich wenn überhaupt so erst in London einzulassen; dort mußte die Atmosphäre günstiger sein als in Paris, wo außerdem bilateralen deutsch-französischen Unterhaltungen - also Unterhaltungen ohne Anlehnung an die wohlwollenden Anglo-Amerikaner - nicht auszuweichen war. Aber angesichts der demonstrativen französischen Hilfsbereitschaft, angesichts einer offenbar erzielten französisch-britisch-amerikanischen Vorverständigung in der Frage einer langfristigen Anleihe für Deutschland und angesichts der Tatsache, daß, anders als bisher, eine französische Regierung erstmals politische Bedingungen offiziell als Bedingungen Frankreichs für eine solche Anleihe genannt hatte, sah sich der Kanzler genötigt, noch in Paris aus der Reserve herauszutreten.

Jedoch retournierte Brüning den von Laval geschlagenen Ball so deftig, daß der Aufschläger das Nachsehen hatte. Seit Monaten fürchteten Brüning und seine engsten Mitarbeiter, daß die Reparationsgläubiger und die USA Deutschland eine hohe langfristige Anleihe zu annehmbaren Bedingungen offerieren könnten. Es war das schon im Herbst 1930 erkannte Problem: Wurden die deutschen Finanzen saniert oder doch stabilisiert und trat danach eine Erholung der deutschen Wirtschaft ein, bestand die Gefahr, daß an die Abschüttelung der Reparationslast erst in grauer Zukunft zu denken war. Jetzt lag das von Großbritannien und den Vereinigten Staaten offenbar bereits abgesegnete Angebot Frankreichs vor, und das war Brüning um so unangenehmer, als ihm angesichts der Lage in Deutschland, wie sie durch die Welle der Abzüge kurzfristiger Kredite nach dem 6. Juni und neuerdings durch die Bankenkrise entstanden war, gar keine Wahl blieb: Er hatte, ganz anders als in Chequers, vor seine Gesprächspartner in London und nun gleich in Paris mit der Bitte zu treten, Deutschland eben jenen langfristigen Kredit zu gewähren, den er selbst nach wie vor überhaupt nicht haben wollte, und überdies mit der weiteren Bitte, die jüngsten Verluste an kurzfristigen Krediten zu ersetzen. Werde die Bitte nicht erfüllt, versicherten der Kanzler und Curtius, sei der finanzielle und wirtschaftliche Zusammenbruch des Deutschen Reiches nicht mehr aufzuhalten ${ }^{118 .}$

117 AdRK, Die Kabinette Brüning, Bd. 2, Nr. 392.

118 Notes of a Conversation held at the Ministry of the Interior, 20.7. 1931, Memorandum Henderson on Discussions in Paris; DBFP, Second Series, Vol. II, Nr. 219, 193. Aufzeichnung Curtius, 18. 7. 1931; PA, R 28255 k. Brünings Behauptung im Kabinett, er habe in Paris keine Anleihe erbeten, diente offensichtlich taktischen Zwecken; AdRK, Die Kabinette Brüning, Bd. 2, Nr. 408. 
Solch dramatische Ankündigung geschah auch im Auftrag des Kabinetts, das unter dem starken Druck der Länder und Kommunen stand, die zum zweiten Mal vom Abzug kurzfristiger Kredite hart getroffen worden waren und finanziell nur noch dahinsiechten. Der Kreditbedarf war evident. Alle Sachverständigen stimmten darin überein, daß die deutsche Wirtschaft allein schon dadurch gekräftigt werden könnte, wenn mit hereinströmenden Geldern ein großer Teil der noch nicht abgezogenen, jedoch stets gefährdeten kurzfristigen Kredite in langfristige Anlagen umgewandelt würde ${ }^{119}$. Da ferner der andere Teil des auch von Brüning auf 500 Millionen Dollar - also 2 Milliarden Reichsmark - bezifferten Kredits nicht zum Stopfen irgendwelcher Löcher im Reichshaushalt hätte verwendet werden dürfen - ebenfalls eine Bedingung der potentiellen Geldgeber-, sondern über die Reichsbank direkt an Unternehmen fließen sollte, die unter Kapitalmangel litten, wäre eine belebende Wirkung auf die Wirtschaft gewiß nicht ausgeblieben, trotz der geringen Kraft des Binnenmarkts und trotz der großen Schwierigkeiten auf den gleichfalls schwachen internationalen Märkten. Innenpolitisch hätte das ausgereicht, um den linken wie den rechten Radikalismus ein gutes Stück zurückzustutzen; einen Beleg liefert der Blick voraus ins Jahr 1933, als es Hitler und der NS-Bewegung gelang, ihre Herrschaft bis zur Jahreswende 1933/34 nicht zuletzt durch die bloße Vorspiegelung einer energischen Kampagne gegen die Arbeitslosigkeit zu festigen.

Brüning war also in Paris starken inneren wie äußeren Pressionen ausgesetzt. Doch zeigte er sich dem Druck gewachsen. Allerdings lag das zu einem guten Teil daran, daß es einem Kanzler, der weniger vom Reichstag als von Reichspräsident und Reichswehr abhing, nicht so schwer fiel wie es einem mit parlamentarischen Majoritäten regierenden Kanzler gefallen wäre, dem französischen Manöver erfolgreich zu begegnen. Hätte etwa ein Kanzler der Weimarer Koalition amtiert, wäre Lavals und Flandins Glaube nicht ganz ohne Grundlage gewesen, endlich habe Frankreich die Möglichkeit, Deutschland ein politisches Moratorium abzuzwingen, weil doch die Reichsregierung in Anbetracht der deutschen Nöte nicht umhin können werde, wirtschaftlicher Vernunft Vorrang vor revisionspolitischen Träumen zu geben ${ }^{120}$. Einem Kanzler mit Brünings Machtbasis konnten die Franzosen jedoch im Augenblick keinen größeren Gefallen tun, als die AnleiheOfferte mit politischen Bedingungen zu verbinden. Sie spielten ihm damit jenes nationale Argument zu, auf das er seit Herbst 1930, als die Idee französischer Finanz- und Wirtschaftshilfe erstmals in offiziellen diplomatischen Gesprächen erörtert worden war, gewartet hatte.

119 So auch in dem Bericht des dann von der Londoner Konferenz bestellten Sachverständigenausschusses, Schulthess', 1931, S. $509 \mathrm{ff}$.

120 Sehr klar ausgesprochen in einer Unterredung zwischen Lord Reading, Laval, Briand und Flandin, am 7. 10. 1931 in Paris; DBFP, Second Series, Vol. II, Nr. 266. 
Brüning hat in jenen Monaten des öfteren, ob in Verhandlungen mit französischen, britischen und amerikanischen Politikern, ob intern, mit großem Ernst und gelegentlich - sogar in Kabinettssitzungen - nicht ohne Pathos erklärt ${ }^{121}$, er werde niemals wirtschaftliche Vorteile mit der Unterschrift unter nationalpolitisch schändliche und schädliche Dokumente - wie etwa einem von Frankreich diktierten politischen Moratorium - erkaufen. Das entsprach sicherlich seiner politischen Grundüberzeugung und der Auffassung der ihn stützenden Gruppierung. Im Moment aber ging es ihm um die Abwehr der Anleihe, und in der diplomatisch-taktischen Situation, die das französische Angebot geschaffen hatte, diente ihm die Beschwörung unverzichtbarer nationaler Interessen und der nationalen Ehre lediglich dazu, ein Geschenk mit Anstand abzulehnen, das ihm angesichts des Ziels seiner Reparationspolitik als Danaergeschenk erscheinen mußte. Hätte die französische Regierung die Kredit-Offerte nicht an ein politisches Moratorium geknüpft, wäre Brüning zweifellos in eine schwierige Lage geraten. Eine ähnlich passende Begründung der Ablehnung des von ihm selbst mit so eindringlicher Rhetorik geforderten Kredits hätte sich nicht leicht finden lassen. Aber zweifellos wäre sie gesucht und am Ende auch entdeckt worden.

Schon einige Wochen vor den Treffen in Paris und London hatte der in der Reparations- und Kreditfrage mittlerweile ganz für den Kurs des Kanzlers gewonnene Staatssekretär v. Bülow an Botschafter v. Hoesch geschrieben, es habe den Anschein, daß „die Gegenseite“ Deutschland auf den Weg neuer Anleihen „abdrängen“ wolle, doch werde man solche Anleihen ablehnen, „selbst wenn sie nicht mit politischen Bedingungen verbunden sind“122. Und wenige Tage nach den Juli-Besprechungen, als Premier MacDonald und Henderson zu einem auch ansonsten nicht unwichtigen Besuch nach Berlin gekommen waren und Brüning der britischen Unterstützung seiner reparationspolitischen Absichten sicher zu sein glaubte, ließ der Kanzler die Berufung auf den politischen Erpessungsversuch Frankreichs denn auch wieder fallen. Die Reichsregierung, so sagte er seinen britischen Gästen, habe den Vorschlag einer langfristigen Anleihe erwogen, nähme sie jedoch den Kredit-Plan, wie ihn die Franzosen vorschlügen, an, bestünde der Effekt nur darin, daß die Reparationsfrage definitiv gegen Deutschland geregelt würde. Vom politischen Moratorium war weiter keine Rede. Was die deutsche Regierung wirklich wolle, erklärte Brüning, sei Hilfe, um über das laufende Jahr wegzukommen ${ }^{123}$.

Genau diese Hilfe bekam die Reichsregierung. Parallel zu den auf Regierungsebene geführten Gesprächen in Paris und London kam es eine Etage

121 In dem Bericht über die Pariser und Londoner Besprechungen, den er dem Kabinett am 25. 7. 1931 erstattete; AdRK, Die Kabinette Brüning, Bd. 2, Nr. 408.

122 Bülow an Hoesch, 8. 6. 1931; PA, R 29506.

123 Record of a Meeting between Mr. MacDonald, Mr. A. Henderson, Dr. Brüning and Dr. Curtius at the Reichskanzlei, Berlin, on July 28, 1931; DBFP, Second Serie, Vol. II, Nr. 228. 
tiefer zu Verhandlungen, in denen unter Mitwirkung von britischen, französischen und amerikanischen Finanziers und Finanzexperten erreicht wurde, der Reichsbank einen stattlichen - und dann mehrmals prolongierten - Stützungskredit zu gewähren, an dem nicht nur die Zentralbanken Großbritanniens und der USA beteiligt waren, sondern auch die Bank von Frankreich $^{124}$. Zugleich brachten es die britische und die amerikanische Regierung fertig, daß jene Investoren aus ihren Ländern, die noch - und zwar immer noch beträchtliche - kurzfristige Kredite in Deutschland stehen hatten, sich ausdrücklich dazu verpflichteten, diese Kredite für eine nicht präzis vereinbarte Frist, doch jedenfalls fürs erste nicht abzuziehen ${ }^{125}$; einer der erhofften Effekte einer langfristigen Anleihe, die Umwandlung kurzfristiger in längerfristige Anlagen und damit ein erheblicher Gewinn an finanzieller Stabilität, hatte also auf solche Weise wenigstens partiell und immerhin, wie angenommen werden durfte, für die schlimmste Krisenperiode doch gesichert werden können. Brünings Spekulation darauf, daß die Ärzte während ihres Konsiliums den Patienten schon nicht einfach sterben lassen würden, erwies sich als richtig.

Um so leichter fiel es dem Kanzler und Außenminister Curtius, dem Anleihe-Projekt noch in Paris mit dem nationalen Argument den Garaus zu machen. Das Argument eignete sich, um Laval und Flandin zu verstehen zu geben, ihr Bestehen auf einem politischen Moratorium mache weitere Gespräche über einen langfristigen Kredit sinnlos ${ }^{126}$; es genügte, um Henderson in längerer, gewundener und - in Anbetracht der beklagten und in der Tat beklagenswerten wirtschaftlichen Lage Deutschlands - von Verlegenheit nicht freier Rede darzulegen, daß Frankreichs Entschlossenheit zur politischen Erpressung das Anleihe-Projekt leider scheitern lasse ${ }^{127}$; und es taugte vortrefflich dazu, die Ablehnung des französischen Angebots gegen einheimische Kritik, wie sie etwa bei den für Finanz- und Wirtschaftsfragen zuständigen Ministern und ihren Sachverständigen mehr oder weniger laut grummelte ${ }^{128}$, zu verteidigen, ja sie sogar als Abwehr eines von der französischen Regierung - die ja mit dem Moratorium selbst noch die Revisionsklausel der Völkerbundssatzung gänzlich unbrauchbar machen wolle - versuchten Ausbaus von Versailles zu rechtfertigen ${ }^{129}$.

124 James, The German Slump, S. $318 \mathrm{f}$.

125 Ebenda.

126 Aufzeichnung Schwerin-Krosigk, 18.7. 1931; AdRK, Die Kabinette Brüning, Bd.2, Nr. 398.

127 Notes of Conversation Henderson - Curtius, 21. 7. 1931; DBFP, Second Series, Vol. II, Nr. 221.

128 Noch am 30.5. 1931 empfahl Reichsbankpräsident Luther in einer Ministerbesprechung, „sich bei gegebener Gelegenheit auf Anleihepläne einzulassen“; AdRK, Die Kabinette Brüning, Bd. 2, Nr. 316.

129 So Bülow dezidiert in einer Aufzeichnung vom 25.9. 1931: „Es wird französischerseits regelmäßig unterstellt und von einem großen Teil unserer Öffentlichkeit angenommen, der deutsch-französische Gegensatz bestehe darin, daß Frankreich den Status quo, insbeson- 
Nach solcher Ergebnislosigkeit des Pariser Treffens durfte auch von der sofort anschließenden Londoner Konferenz nichts Positives oder überhaupt irgendwie Entscheidendes erwartet werden. Dem Anschein nach brachten denn auch die Londoner Gespräche in ihrem ersten Stadium nichts anderes als die sozusagen offizielle Wiederholung des inoffiziellen Resultats von Paris. Laval und Flandin präsentierten ihr Anleihe-Projekt, da aber hierüber Deutsche und Franzosen bereits in Paris negativ entschieden hatten, geschah schon die Präsentation recht lustlos ${ }^{130}$, und danach ließen die Vertreter Großbritanniens und der sechs eingeladenen Staaten die Idee sanft entschlafen. Das wäre sicherlich nicht möglich gewesen, hätten die Briten auf einer ernsthaften Behandlung bestanden. MacDonald, Henderson und Schatzkanzler Philip Snowden taten das indes nicht, teils weil es ihnen angesichts der deutschen Haltung als zwecklos erschien, in erster Linie jedoch weil sie mittlerweile selbst zu Gegnern des Projekts geworden waren. Zwar gaben sie sich wie seit Wochen so auch jetzt in London große Mühe, die deutschen Gäste zu irgendeiner Versicherung politischen Wohlverhaltens $\mathrm{zu}$ bewegen. In einer Unterredung mit Curtius und Bülow, die im Foreign Office stattfand und in der Curtius sagte, ohne neue Kredite werde Deutschland zusammenbrechen, schlug Henderson eine internationale Deklaration vor, die Staatengesellschaft werde fünf Jahre lang heikle politische Fragen ruhen lassen; eine solche Deklaration könne die Reichsregierung doch unterschreiben, zumal sie ständig behaupte, Probleme wie den „Polnischen Korridor" noch gar nicht aufrollen zu wollen. Curtius erwiderte, Deutschland könne nicht auch noch auf die Rechte verzichten, die Artikel 19 der Völkerbundsatzung biete. Henderson stellte klar, daß er nicht einen Verzicht verlange, sondern lediglich ein befristetes Ruhenlassen. Obwohl ein derartiges Moratorium, wie inzwischen einige britische und französische Politiker und Diplomaten zu ihrem Schrecken bemerkt hatten, Deutschland im Grunde geradezu das Recht zugestand, nach Ablauf der vereinbarten Pause den aktiven Kampf um seine revisionspolitischen Forderungen aufzunehmen, blieben Curtius und Bülow unzugänglich. Der britische Außenminister geriet dadurch so in Zorn, daß er ausrief, das deutsche Verhalten laufe darauf hinaus, triviale Melodien zu fiedeln, während Rom brenne ${ }^{131}$. Aber an einer politischen Erklärung der Reichsregierung, die Europa und insbesondere Frankreich beruhigen sollte, lag den Briten, wie sich

dere den Versailler Vertrag, unverändert aufrecht erhalten, Deutschland dagegen diesen revidieren wolle. In Wirklichkeit ist Frankreich bestrebt, den Versailler Vertrag auszubauen“; PA, R 29517.

130 The London Conference, 1931, Stenographic Notes; DBFP, Second Series, Vol. II, Appendix I.

131 Notes of a Conversation between Mr. A. Henderson and Dr. Curtius on July 21, 1931; DBFP, Second Series, Vol. II, Nr. 221. 
bald noch deutlicher zeigte, nicht mehr im Zusammenhang mit dem Anleihe-Projekt.

Nach dem Versanden des Kredit-Themas konzentrierten sich die in London konferierenden Politiker auf die beiden anderen für Deutschland wichtigen Probleme: auf die Stützung der Reichsbank und auf die Sicherung der noch in Deutschland angelegten kurzfristigen Auslandskredite. Das geschah aus schierer konferenzpolitischer Verlegenheit. Nachdem die französische und die deutsche Regierung die Erörterung des zentralen Punkts der Tagesordnung in gemeinsamer Anstrengung unmöglich gemacht hatten, gab es eigentlich keinen sachlichen Grund mehr, die Konferenz fortzusetzen. Mit einem Abbruch hätten jedoch die Teilnehmer, inmitten der schwersten internationalen Krise von Wirtschaft und kapitalistischem System, auf blamabelste Weise ihre Unfähigkeit eingestanden, die Überwindung der Krise auch nur in Angriff zu nehmen, und so stürzten sie sich voll Eifer auf zwei Fragen, die wohl überaus dringlich waren, aber nicht in der Zuständigkeit der Regierungen lagen, sondern anderswo, nämlich in der Bankwelt, konkret diskutiert, entscheidungsreif gemacht und entschieden wurden. Die Regierungen hatten ja, jedenfalls formal, nicht die Befugnis, den zuständigen Zentralbanken oder gar den involvierten Privatbanken einfach Weisungen zu erteilen.

Gewiß hatte es Gewicht, wenn die Londoner Konferenz Probleme, die evidentermaßen von eminenter wirtschaftlicher und politischer Bedeutung waren, debattierte und am Ende zu diesen Problemen Empfehlungen an die Banken formulierte: 1. Der 100-Millionen-Dollar-Kredit der Notenbanken, der vor kurzem unter der Führung der Bank für Internationalen Zahlungsausgleich der Reichsbank zur Verfügung gestellt wurde, solle am Fälligkeitstag um drei Monate verlängert werden! 2. Kurzfristige Kredite sollten vorerst aus Deutschland nicht abgezogen werden! Aber es handelte sich eben doch nur um Empfehlungen, und wenn auch den Empfehlungen gemäß verfahren wurde, so war das neben dem Einfluß der Regierungen fast noch mehr der in der Banken- und Geschäftswelt wieder - im Vergleich zu den Vorjahren - stärker gewordenen wirtschaftlichen Rationalität zu danken. Die dritte Empfehlung der Konferenz ging dahin, unter den Auspizien der Bank für Internationalen Zahlungsausgleich ein Komitee von Experten einzusetzen, dessen Mitglieder - benannt von den Leitern der interessierten Notenbanken - den unmittelbaren Bedarf Deutschlands an neuen Krediten und die Möglichkeit der Umwandlung kurzfristiger in langfristige Kredite prüfen sollten ${ }^{132}$.

Dem Anschein nach war also das Ergebnis der Londoner Besprechungen wenig eindrucksvoll, und viele Teilnehmer der Konferenz hatten selbst ein

132 The London Conference, 1931, Stenographic Notes; DBFP, Second Series, Vol. II, Appendix I. 
recht ungutes Gefühl. So sagte Emil Francqui, Direktor der Société Géneral de Belgique und einer der drei belgischen Delegierten, während der Debatten einmal sarkastisch, vierzehn Tage zuvor hätten in Basel Vertreter der Zentralbanken getagt und seien zu dem Schluß gekommen, sie selbst könnten gar nichts tun und müßten die Probleme wieder den Regierungen anheimstellen, jetzt in London würden die Probleme nach stundenlangen Diskussionen an die Notenbanken zurückverwiesen: „Der Ball scheint hin und her geworfen zu werden, und das kann noch lange so weitergehen. “133

Tatsächlich aber markierte die Londoner Konferenz einen entscheidenden Wendepunkt. Wichtigstes - wenn auch öffentlich noch nicht sichtbares - Resultat war die definitive Trennung sowohl britischer wie amerikanischer Intentionen von französischer Deutschlandpolitik im allgemeinen und französischer Reparationspolitik im besonderen. Nach wie vor glaubte die Pariser Regierung, am Young-Plan festhalten und für ihre Zustimmung zu Lockerung und Milderung des Plans politische Konzessionen Deutschlands bekommen zu können. Wenn Laval in den Pariser Gesprächen und während der Londoner Debatten hartnäckig darauf bestand, Voraussetzung der Überwindung der europäischen Wirtschaftsnöte sei die Rückgewinnung von Vertrauen und Sicherheit ${ }^{134}$, so meinte er damit die Festigung des Vertrauens in die Sicherheit der Grenzen in Europa, und zwar durch den erkennbaren Beginn der deutschen Aussöhnung mit dem Status quo. Und er glaubte ferner, für den Pariser Kurs noch immer die Billigung und Rückendeckung zumindest Großbritanniens zu haben. In London vollendete sich jedoch jene Wandlung der britischen Politik, die sich schon seit einigen Monaten vorbereitet hatte. Wenn MacDonald oder Henderson in den Diskussionen und Unterredungen davon sprachen, daß Europa - wie die Welt Vertrauen und Sicherheit brauche, so redeten sie nicht vom territorialen Status quo auf dem europäischen Kontinent, vielmehr meinten sie damit, Europa und die Welt müßten darauf bauen können, daß die Finanzen, die Wirtschaft und der Kredit Deutschlands nach Ablauf des Hoover-Moratoriums nicht durch die simple Wiederaufnahme des Young-Plans erneut belastet und dadurch abermals ruiniert würden. Und die britische Auffassung war mittlerweile sachlich richtig geworden. Auch wenn die Reparationen anfänglich und im Grunde mit der deutschen und der globalen Wirtschaftskrise gar nichts zu tun gehabt hatten, ob man die Ursachen oder die laufende Verschärfung in den Blick nimmt, so hatte die inzwischen entstandene Überzeugung, daß ein Zusammenhang bestehe, diesen Zusammenhang tatsächlich geschaffen. Wie Sir Robert Vansittart während der Pariser Unterhaltungen an Lord Tyrrell und Henderson schrieb: „Nach Ansicht aller un-

133 Ebenda.

134 So sagte er am 19.7.1931 zu seinen britischen und deutschen Kollegen: „Was not tut, ist das Versprechen [der deutschen Regierung], daß Europa von nun an in Frieden arbeiten kann.“ DBFP, Second Series, Vol. II, Nr. 219. 
serer Finanz-Autoritäten ist die derzeitige Krise in Deutschland auf Mangel an Vertrauen zurückzuführen, sowohl im Ausland wie im Inland, und zwar im Hinblick auf die Frage, ob es Deutschland möglich sein wird, seine wirtschaftliche und finanzielle Stabilität zu bewahren, solange auf seinen Reparationsverpflichtungen bestanden wird." Ohne Wegfall der Reparationen werde es keine Anleihen geben ${ }^{135}$.

An solchem Verständnis der Situation war dann auch der Vorschlag des amerikanischen Außenministers Stimson orientiert, den Kreditbedarf Deutschlands durch eine unabhängige Expertenkommission prüfen zu lassen. Das klang zwar eher nach Hilflosigkeit, klang nach dem von Francqui mit Spott bedachten Hin und Her zwischen Politik und Wirtschaft. Tatsächlich war es nichts dergleichen. Daß die Londoner Konferenz den Vorschlag annahm und die BIZ wie die Zentralbanken entsprechend instruierte - das immerhin lag in der Macht der Regierungen -, bedeutete in Wahrheit den Anfang vom Ende des Young-Plans, der Reparationen überhaupt. Unbemerkt von Franzosen und Deutschen verschob die Beauftragung einer Expertenkommission, wie von Stimson und den mit ihm verbündeten Briten beabsichtigt, die Frage der Zahlungen des Deutschen Reiches an ausländische Regierungen vom Felde der Politik auf das Feld der Wirtschaft. Wohl hatte auch der Übergang vom Dawes-Plan zum Young-Plan auf den Beratungen eines Sachverständigen-Gremiums beruht. Aber die Experten von 1928/29 hatten noch in einer Periode relativer wirtschaftlicher Normalität deliberieren können und daher die politische Seite des Reparationsproblems berücksichtigen müssen. Konkret hieß das: Daß Deutschland Reparationen zu zahlen habe, hatte damals gar nicht zur Debatte gestanden; der YoungAusschuß hatte lediglich zu prüfen, wieviel das Reich zahlen könne. Jetzt, im Sommer 1931, standen die Dinge ganz anders. Die von den Leitern der Zentralbanken nominierte und nach ihrem britischen Mitglied Sir Walter T. Layton, dem Herausgeber des „Economist“, genannte Kommission nahm ihre Tätigkeit in einem Augenblick auf, da eine globale Wirtschaftskrise ihren vorläufigen Tiefpunkt erreicht hatte, und mußte also ihre Arbeit, dies schien die Lage gebieterisch zu fordern, unter die Alleinherrschaft wirtschaftlicher Vernunft stellen. Mit der Formulierung des Auftrags hatten das die in London tagenden Regierungen - ohne daß, wie gesagt, Franzosen und Deutsche dessen so recht gewahr geworden wären - mehr als anerkannt, nämlich zur Leitlinie erhoben: Die Kommission sollte ja nicht die Zahlungsfähigkeit, sondern die Kreditbedürftigkeit des Deutschen Reiches untersuchen. Und wenn die Kommission, was nach menschlicher Voraussicht erwartet werden mußte, deutsche Kreditbedürftigkeit feststellte, war das der Todesstoß für den Young-Plan. Angesichts des gewandelten Bewußtseins schlossen nunmehr Anleihen an Deutschland deutsche Reparations-

135 Vansittart an Lord Tyrrell, 17. 7. 1931; DBFP, Second Series, Vol. II, Nr. 216. 
zahlungen aus - und umgekehrt. An eine Wiederholung des wirtschaftlich so sinnlosen Geldkreislaufs, der die Jahre 1925 bis 1930 charakterisiert hatte, konnte und wollte niemand mehr denken. Daraus ergab sich, noch effektiver als in manchen Momenten bisher schon, eine verdeckte Allianz zwischen Anglo-Amerikanern und Deutschen; sie bestimmte die Behandlung des Reparationsproblems in den folgenden Monaten.

Auch Reichskanzler Brüning begriff die Treffen in Paris und London als ersten Abschnitt eines neuen Kapitels der Reparationspolitik. Zwar verstand er zunächst nicht, welche Bedeutung der Einsetzung des Layton-Ausschusses tatsächlich zukam. Vielmehr sah er hier eine Gefahr. Als Grund wirkte, wie so oft bei ihm, die Furcht, daß Deutschland eine Anleihe angeboten werden könnte, die nur noch um den Preis schwersten außenpolitischen Schadens abzulehnen sei ${ }^{136}$. Als in London zunächst vorgeschlagen wurde, die Mitglieder der Kommission zur Prüfung der deutschen Kreditbedürftigkeit von der Bank für Internationalen Zahlungsausgleich nominieren zu lassen, schlug Brüning - praktisch sein einziger aktiver Beitrag zur Konferenz - eine heroische Abwehrschlacht, da er die BIZ unter französischem Einfluß wähnte - was nur einen geringen Wahrheitskern hatte - und mithin eine französischen Wünschen gefügige Kommission befürchten zu müssen glaubte; ein solches Gremium, so meinte er, werde unweigerlich bestrebt sein, Deutschland eine langfristige Anleihe aufzudrängen ${ }^{137}$. Mit britischer Unterstützung erreichte er dann jedoch die Nominierung durch die Leiter der Notenbanken, und es war für die britische Grundhaltung bezeichnend, daß das Argument des Kanzlers, die BIZ habe in Deutschland einen schlechten Ruf, weil sie als "Rudiment der Reparationskonferenz" gelte, bei den britischen Konferenzteilnehmern, namentlich bei Schatzkanzler Snowden, volles Verständnis fand ${ }^{138}$. Freilich gefiel Brüning die Kommission auch in ihrer endgültigen Zusammensetzung nicht so recht, obwohl diese ja auf ihn selbst zurückging; nach wie vor witterte er eine allzu große Hinneigung zu französischen Interessen. $\mathrm{Da}$ dem Layton-Ausschuß eine derartige Hinneigung - jedenfalls zu den französischen Anleiheprojekten kraft seiner Zweckbestimmung sozusagen eingeboren schien, müssen die Ängste des Kanzlers, angesichts seiner reparationspolitischen Zielsetzung, als nicht ganz unberechtigt gelten.

In einer anderen Hinsicht aber gewann Brüning aus den Pariser und Londoner Gesprächen einen klaren und zutreffenden Eindruck: Zwischen Anglo-Amerikanern - vor allem Briten - und Franzosen sei, so diagnostizierte er mit Recht, in der grundsätzlichen Einstellung zum Reparationsproblem und zu den damit zusammenhängenden Fragen offenbar ein schroffer und

136 Köpke an Hoesch, 28. 7. 1931; PA, R 70505.

137 Ebenda.

138 The London Conference, 1931, Stenographic Notes; DBFP, Second Series, Vol. II, Appendix I. 
überdies anscheinend unheilbarer Gegensatz entstanden. Während Frankreich eine möglichst einschränkende Auslegung des Hoover-Moratoriums durchsetzen und die Weitergeltung des Young-Plans sichern wolle, halte die britische Regierung jede Einschränkung der amerikanischen Idee für falsch; vor allem aber habe niemand in London die Absicht, Deutschland wieder auf den Young-Plan zu verpflichten ${ }^{139}$. Letztere Meinung war mehr als Interpretation britischen Verhaltens. In einem Brief an Botschafter v. Hoesch schrieb Ministerialdirektor Köpke, Sir Walter Layton, der britische Vorsitzende des nun gebildeten Ausschusses, habe „in einem vertraulichen Privatgespräch dem deutschen Delegationsführer offen erklärt, daß er eine Wiederaufnahme der Young-Zahlungen nach dem Feierjahr für ausgeschlossen halte“. Die endgültige Regelung der Reparationsfrage sei seiner Meinung nach nur in der Form denkbar, daß Deutschland noch kleinere Beträge an Frankreich und Belgien zahle: "Alles andere müsse fortfallen. "140 Daß Sir Walter hier nicht nur seine eigene Ansicht äußerte, durfte getrost unterstellt werden.

Reichskanzler Brüning zog selbstverständlich den Schluß, daß der britisch-französische Gegensatz - den er in einer Ministerbesprechung merkwürdigerweise als „erschreckend tief“ bezeichnete ${ }^{141}$ - künftig als sicherer Faktor einkalkuliert und in der Tat zur Erzwingung des Endes der Reparationen ausgenützt werden könne. Die Hauptarbeit gedachte er dabei, wie ohne klareres Verständnis der Londoner Politik bisher schon, den Briten zu überlassen. Als sich Premierminister MacDonald und Außenminister Henderson - den deutschen Besuch in Chequers erwidernd - am 27. und 28. Juli in Berlin aufhielten, trat die neue Qualität im deutsch-britischen Verhältnis bereits deutlich hervor. In einer Unterhaltung, die im Garten der Reichskanzlei stattfand, schlug MacDonald seinen Gastgebern Brüning und Curtius vor, bei der - als selbstverständlich angenommenen - Fortsetzung der deutsch-französischen Gespräche über wirtschaftliche und reparationspolitische Fragen möglichst bald auch Großbritannien wieder einzuschalten. Er begründete das mit dem britischen Interesse an jenen Fragen; die Regierung Seiner Majestät dürfe auch nicht noch einmal, wie bei den amerikanischfranzösischen Verhandlungen über das Hoover-Moratorium, mit einer als Fait accompli einfach hinzunehmenden Vereinbarung konfrontiert werden. Doch ging der Premier über diese Binsenwahrheit einen langen Schritt hinaus und bot den beiden Deutschen in kaum noch verhüllenden Wendungen an, französische Engstirnigkeit und Engherzigkeit - welche Worte er natür-

139 Köpke an Hoesch, 28. 7. 1931; PA, R 70505.

140 Ebenda.

141 AdRK, Die Kabinette Brüning, Bd. 2, Nr. 408. 
lich nicht benutzte - durch britisch-deutsches Zusammenwirken zu überwinden ${ }^{142}$.

Nicht anders Henderson. Curtius bewies einmal mehr seinen Mangel an politisch-diplomatischem Verständnis, indem er mit der Behauptung reagierte, zunächst solle Deutschland mit Frankreich allein konversieren, nicht um bald ein brauchbares Ergebnis zu erzielen, sondern um den guten Willen der Deutschen darzutun; daß der Kanzler und er selbst zuletzt Bereitschaft zu direktem Verkehr mit der französischen Regierung gezeigt hätten, sei doch schon - so setzte er in charakteristischer Fehleinschätzung der Grundelemente der gegebenen Situation und in ebenso charakteristischer Überschätzung des Effekts seines persönlichen Auftritts in Paris hinzu - von günstigem Einfluß auf die politische Atmosphäre gewesen. Brüning hingegen, der bereits von der Londoner Konferenz ein richtigeres Urteil über die britischen Absichten mitgebracht und in den wenigen Tagen seither mehrere Bestätigungen dieses Urteils erfahren hatte, verstand sofort, was ihm MacDonald und Henderson sagen wollten. Er nahm den zugespielten Ball auf und betonte, wenn die in der Tat weiterhin zu führenden bilateralen Gespräche zwischen Deutschland und Frankreich einen bestimmten Punkt erreicht hätten, sei die britische Intervention „essentiell“143.

Eine produktive Fortsetzung der deutsch-französischen Gespräche ließ in der Tat, wie MacDonalds Offerte ja unterstellte, auf sich warten; der Morast gegensätzlicher Positionen lähmte jede Bewegung. Die französische Regierung fand nicht - dabei der Zustimmung einer Mehrheit der Bevölkerung sicher - das Herz, sich auf den baldigen Abschied von Young-Plan und Reparationen einzurichten. Auf der anderen Seite weigerte sich die deutsche Regierung - auch sie im Sinne einer Majorität handelnd - nach wie vor, sich auf ein irgendwie geartetes politisches Moratorium einzulassen. Daß dies die Briten immer noch dringend wünschten - nicht mehr um Paris eine Anleihe an Deutschland schmackhaft zu machen, sondern um Frankreichs Einstellung zum Young-Plan aufzulockern -, blieb ohne Echo in Berlin. $\mathrm{Daß}$ die deutsch-österreichische Zollunion allmählich preisgegeben wurde, konnte in Paris und auch in London nicht als deutsche Konzession registriert werden, war doch der eigentliche Grund der Preisgabe ganz simpel die Tatsache, daß die Reichsregierung den österreichischen Partner verloren hatte.

In allen übrigen revisionspolitischen Fragen zeigten sich Brüning, Curtius und Bülow so hart wie eh und je. Tatsächlich glaubten sie sogar, vom Blick auf die britisch-französischen Differenzen sichtlich munterer gestimmt, sich mittlerweile einiges herausnehmen zu dürfen. Obwohl sie bei ihrer Repara-

142 Gespräch zwischen MacDonald, Henderson, Brüning und Curtius in Berlin, 28. 7. 1931; DBFP, Second Series, Vol. II, Nr. 228.

143 Ebenda. 
tionspolitik auf britisches und amerikanisches Wohlwollen angewiesen waren und sehr gut wußten, welch großen Wert sowohl London wie Washington auf Erfolge der bevorstehenden Abrüstungskonferenz legten, scheuten sie nicht davor zurück, in Unterredungen mit Briten und Amerikanern zu erklären, falls London und Washington in den Abrüstungsproblemen nicht zu einer Deutschland befriedigenden Vorverständigung bereit seien, könne es sehr leicht sein, daß das Reich an der Konferenz gar nicht teilnehmen werde ${ }^{144}$. Obschon die französische Regierung häufig genug - und eben auch im Sommer 1931 - bekräftigte, Frankreich denke gar nicht daran, ohne zusätzliche und zuverlässige Sicherheitsgarantien abzurüsten, und obschon Kriegsminister Maginot gerade 1931 den beschleunigten Ausbau eines dann nach ihm benannten - modernen Festungsgürtels an der französischen Ostgrenze durchsetzte, der zwar als defensiv, aber doch nicht als Abrüstungsmaßnahme eingestuft werden konnte, obschon also auch Frankreich die Anglo-Amerikaner in der Abrüstungsfrage laufend verstimmte, war die Berliner Drohung doch recht kühn. Wie sehr in Berlin das Selbstbewußtsein gestiegen war, verriet Brüning auch dadurch, daß er am 28. Juli, selbst noch auf dem Rückzug aus dem Zollunion-Abenteuer, MacDonald und Henderson in der Reichskanzlei klipp und klar sagte, die während des Pariser Treffens lancierte französische Idee einer Donaukonföderation, von Österreich bis Bulgarien, sei für Deutschland völlig unannehmbar ${ }^{145}$. All das war, da deutsch-britische Interna naturgemäß auch in Paris bekannt wurden, dem deutsch-französischen Dialog nicht förderlich.

Am 29. Juli berichtete Hoesch über ein Gespräch mit Berthelot, dem Generalsekretär des französischen Außenministers. Berthelot habe konstatiert, die Treffen von Paris und London hätten zwar keine konkreten Ergebnisse, aber doch „einen stimmungsgemäßen Erfolg“ gebracht. Ferner habe der Generalsekretär schmeichelhafte Worte über seine erfreulichen Unterhaltungen mit Staatssekretär v. Bülow gefunden, der "sowohl den Eindruck eines guten Deutschen wie auch eines intelligenten Politikers" mache. Im übrigen sei von Berthelot die Hoffnung geäußert worden, daß eine weitere Konferenz im Herbst bessere Ergebnisse zeitigen werde. Resigniert empfahl Hoesch „kleine Schritte der Verständigung“146. Bülow reagierte postwendend positiv, mußte jedoch warnend einschränken: „Was wir brauchen, ist deutsch-französische Zusammenarbeit oder Plan einer solchen auf einem Gebiet, das öffentliches Interesse fesselt, ohne notwendig von wirtschaftlicher oder politischer Bedeutung zu sein. Wir suchen bereits angestrengt nach einer solchen Lösung (die schwer zu finden ist). "Im Amt wäre man

144 Notes of Conversation Henderson - Curtius, 21. 7. 1931; DBFP, Second Series, Vol. II, Nr. 221.

145 Gespräch zwischen MacDonald, Henderson, Brüning und Curtius in Berlin, 28. 7. 1931;

DBFP, Second Series, Vol. II, Nr. 228.

146 Hoesch an Bülow, 28. 7. 1931; PA, R 70505. 
Hoesch, so schloß Bülow, „für Einfälle dankbar“147. Doch da war guter Rat teuer. Ende September kamen, wie in Paris und London vereinbart, Laval und Außenminister Briand nach Berlin. Briand besuchte, sichtlich bewegt, das Grab Stresemanns. Alles in allem nahm der Aufenthalt der französischen Gäste einen angenehmen Verlauf. Das lag aber in erster Linie daran, daß weder Laval und Briand noch ihre deutschen Gastgeber ein ernsthaftes Wort über Politik verloren. Der Beschluß, eine deutsch-französische Wirtschaftskommission ins Leben zu rufen, war nur zur Verschönerung des Abschlußkommuniqués bestimmt ${ }^{148}$.

Unmittelbar vor MacDonald und Henderson war auch der amerikanische Außenminister Stimson nach Berlin gekommen. Sein Besuch brachte ebenfalls keinen greifbaren politischen Erfolg. Eine Audienz bei Reichspräsident v. Hindenburg war vorgesehen, und Staatssekretär v. Bülow reagierte entsetzt, als er hörte, der Feldmarschall wolle die Gelegenheit benutzen, dem Repräsentanten der Vereinigten Staaten die deutsche Mißachtung der belgischen Neutralität im August 1914 als unabweisbare Aushilfe in einer unerwartet eingetretenen Notlage des Deutschen Reiches zu erklären; mit solchen Märchen könne kein Eindruck gemacht werden, schrieb Bülow, schließlich sei es kein Geheimnis mehr, daß die Adjutanten der zum Einfall in Belgien bestimmten Regimenter die entsprechenden Befehle schon seit Jahren in der Schublade hatten ${ }^{149}$. Die Intervention blieb nicht ganz ohne Wirkung, aber ein Privatissimum über die Friedfertigkeit, die den preußischen Generalstab wie stets so auch im Sommer 1914 beseelt habe, mußte sich Stimson schon anhören. Der Amerikaner zog sich mit Anstand aus der Affäre, indem er versicherte, er sei überzeugt davon, „daß der Herr Reichspräsident kein Freund des Krieges gewesen sei, sondern friedliebend; er wisse sehr wohl, daß der Herr Reichspräsident im Ruhestand gelebt habe und erst auf den Ruf des Vaterlandes zu den Waffen geeilt sei“. Im übrigen hegten weder er noch die Mehrheit des amerikanischen Volkes feindliche Gefühle oder Bitterkeit, die auf den Krieg zurückgingen. Das zeige sich am besten daran, wie gut das amerikanische Volk die Hoover-Botschaft aufgenommen habe und wie groß auch jetzt noch die Bereitschaft Amerikas sei, „Deutschland in dieser schweren Zeit weiterzuhelfen"150. Immerhin konnte derart freundlichen Worten entnommen werden, daß der spätestens in Lon-

147 Bülow an Hoesch, 30. 7. 1931; PA, R 70505.

148 Aufzeichnung Pünder über Besprechung des Reichskanzlers mit dem französischen Ministerpräsidenten, 27. 9. 1931, Aufzeichnung Curtius über Besprechung mit den Mitgliedern der französischen Regierungsdelegation, 27. 9. 1931; AdRK, Die Kabinette Brüning, Bd. 2, Nr. 489, 490. Dazu auch Rumbold an Lord Reading, 29. 9. 1931; DBFP, Second Series, Vol. II, Nr. 255.

149 Bülow an Meissner, 25. 7. 1931; PA, R 29468.

150 Aufzeichnung Meissner über den Empfang des amerikanischen Außenministers Stimson bei Reichspräsident v. Hindenburg, 27. 7. 1931; AdRK, Die Kabinette Brüning, Bd.2, Nr. 410. 
don gewonnene Eindruck nicht falsch sei, in der Reparationsfrage stünden die USA an der Seite Großbritanniens und nicht hinter Frankreich.

So sahen Brüning und die Reichsregierung, wenn sie ihre britischen und amerikanischen Erfahrungen prüften, auch keinen Anlaß, das französische Beharren auf politischen Konzessionen des Reiches sonderlich ernst zu nehmen, obwohl ihnen - wie auf der anderen Seite den französischen Politikern - von allen Seiten, nur nicht von der Sowjetunion und Italien, eindringlich gepredigt wurde, die gedeihliche Entwicklung des europäischen Kontinents hänge von der deutsch-französischen Verständigung ab. Die These war gewiß grundsätzlich richtig, als Leitprinzip praktischer Politik taugte sie jedoch, nach schlimmen Erlebnissen beider Länder, erst zwanzig Jahre später. Im Augenblick war sie unanwendbar, da die potentiellen Partner auf unvereinbaren Positionen standen und diese Positionen nicht verlassen zu dürfen - und nicht verlassen zu müssen - meinten. Die Bewegung, die gebraucht wurde, um irgendwelche Lösungen wenigstens für die akuten wirtschaftlichen und politischen Probleme zu finden, mußte anders erzeugt werden. 